\title{
A sensitivity study for far infrared balloon-borne limb emission sounding of stratospheric trace gases
}

\author{
J. Xu, F. Schreier, P. Vogt, A. Doicu, and T. Trautmann \\ DLR - German Aerospace Center, Remote Sensing Technology Institute, Oberpfaffenhofen, \\ 82234 Weßling, Germany
}

Received: 29 January 2013 - Accepted: 1 May 2013 - Published: 14 May 2013

Correspondence to: J. Xu (jian.xu@dlr.de)

Published by Copernicus Publications on behalf of the European Geosciences Union.

\begin{abstract}
This paper presents a sensitivity study performed for trace gases retrieval from synthetic observations by TELIS (TErahertz and submillimeter LImb Sounder) which is a stratospheric balloon-borne cryogenic heterodyne spectrometer. Issues pertaining 5 to hydroxyl radical $(\mathrm{OH})$ retrieval from the far infrared measurements by the $1.8 \mathrm{THz}$ channel are addressed. The study is conducted by a retrieval code PILS (Profile Inversion for Limb Sounding) developed to solve the nonlinear inverse problems arising in the analysis of infrared/microwave limb sounding measurements. PILS combines a line-by-line forward model with automatic differentiation for computing Jacobians and 10 employs regularized nonlinear least squares inversion. We examine the application of direct and iterative regularization methods and evaluate the performance of singleand multi-profile retrievals. Sensitivities to expected errors in calibration procedure, instrumental knowledge and atmospheric profiles have been analyzed. Nonlinearity effect, inaccurate sideband ratio, and pointing error turned out to be the dominant error

15 sources. Furthermore, the capability of multi-channel simultaneous retrieval from the far infrared and submillimeter data has been investigated. The errors and averaging kernels infer that the quality of the obtained hydrogen chloride $(\mathrm{HCl})$ can be improved by significantly better exploitation of information from the observations.
\end{abstract}

\section{Introduction}

20 Far infrared and submillimeter limb sounding is a well-established technique for atmospheric remote sensing because numerous trace gases have features in this spectral range. Furthermore, emission observations are independent of sunlight and hence can contribute to the understanding of the diurnal cycles of chemical processes. In addition, aerosols and ice clouds have negligible effect, which also makes the far infrared and submillimeter observations advantageous. The latest spaceborne missions comprise SMR (Sub-Millimetre Radiometer) (Murtagh et al., 2002) on the Odin 
satellite launched in 2001, MLS (Microwave Limb Sounder) (Waters et al., 2006) in 1991 and 2004 aboard the UARS and Aura satellites, respectively, and SMILES (Superconducting subMIllimeter-wave Limb-Emission Sounder) (Kikuchi et al., 2010) from October 2009 to April 2010. In particular, Aura/MLS has the ability to measure thermal emission from the far infrared (Terahertz) spectral range.

TELIS (TErahertz and submillimeter LImb Sounder) is a new balloon-borne cryogenic heterodyne spectrometer designed to investigate the vertical distribution of stratospheric trace gas species associated with ozone depletion and climate change. The instrument utilizes state-of-the-art superconducting heterodyne technology and

10 allows limb sounding of the Earth's atmosphere with high spectral resolution and long flight duration. TELIS was mounted on a stratospheric balloon gondola together with the MIPAS-B (Michelson Interferometer for Passive Atmospheric Sounding - Balloon) instrument (Friedl-Vallon et al., 2004), developed by the Karlsruhe Institute of Technology (KIT), and mini-DOAS (Differential Optical Absorption Spectrometer) operated

15 by the University of Heidelberg. From a flight altitude of $30-40 \mathrm{~km}$, TELIS scans the stratosphere and upper troposphere with 1.5-2 km altitude sampling. The combination of TELIS and MIPAS-B yields a wide range of the electromagnetic spectrum for atmospheric research and offers great synergies for cross-validation of measured chemical constituents. In addition, TELIS serves as a technology demonstrator to future space-

20 borne limb sounders. The instrument has participated in three scientific campaigns in Kiruna, Sweden from March 2009 to March 2011.

TELIS was developed by a consortium of European institutes that include the German Aerospace Center (DLR), the Netherlands Institute for Space Research (SRON), and the Rutherford Appleton Laboratory (RAL) in the United Kingdom. The ambitious spectral coverage of the TELIS instrument is accomplished by use of three frequency channels: a highly compact $500 \mathrm{GHz}$ channel, a 480-650 GHz channel (de Lange et al., 2010) based on the Superconducting Integrated Receiver (SIR) technology, and a tunable 1.8 THz channel (Suttiwong et al., 2009) with enhanced stability provided by RAL, SRON, and DLR, respectively. The incoming atmospheric radiation is transmitted from

a dual offset Cassegrain telescope through the front-end transfer optics where the signals are separated and coupled into each dedicated channel (Suttiwong, 2010).

The 1.8 THz channel measures the signal at a local oscillator (LO) frequency $f_{\mathrm{LO}}$ between 1790 and $1880 \mathrm{GHz}$. The measured spectrum is then generated from the 5 two sidebands with respect to the LO frequency since the TELIS instrument operates in double sideband (DSB) mode. In case of the $1.8 \mathrm{THz}$ channel the spectrum is recorded in the intermediate frequency $f_{\mathrm{IF}}$ domain ranging from approximately 4 to $6 \mathrm{GHz}$ ( $2 \mathrm{GHz}$ spectral bandwidth). The signal is split into four $500 \mathrm{MHz}$ autocorrelator segments. Thus, the measured spectrum covers the frequency domains at $f_{\mathrm{LO}}-f_{\mathrm{IF}}$ and $10 f_{\mathrm{LO}}+f_{\mathrm{IF}}$. For the $480-650 \mathrm{GHz}$ channel $f_{\mathrm{IF}}$ ranges from 5 to $7 \mathrm{GHz}$.

The primary scientific goal of the TELIS/MIPAS-B/mini-DOAS flight has been to measure the time-dependent chemistry of chlorine $(\mathrm{Cl})$ and bromine $(\mathrm{Br})$, and to achieve the closure of chemical families $\left(\mathrm{NO}_{y}, \mathrm{Cl}_{y}, \mathrm{Br}_{\mathrm{y}}, \mathrm{HO}_{\mathrm{x}}\right)$ inside the polar vortex. Regarding the TELIS instrument, the main target of the $1.8 \mathrm{THz}$ channel is the hydroxyl radical $(\mathrm{OH})$.

15 Further stratospheric species $\mathrm{HO}_{2}, \mathrm{HCl}, \mathrm{HOCl}, \mathrm{O}_{3}, \mathrm{O}_{2}, \mathrm{CO}, \mathrm{NO}, \mathrm{NO}_{2}$, and $\mathrm{H}_{2} \mathrm{O}$ including its isotopologues can also be measured in the frequency range of $1790-1880 \mathrm{GHz}$. $\mathrm{OH}$ is a key reactive species for photochemical reactions that regulate ozone throughout most of the stratosphere and mesosphere. The demand and interest of having the capability to measure the $\mathrm{OH}$ radical in the atmosphere has been consequently 20 increasing.

$\mathrm{OH}$ possesses pairs of triplets in the far infrared spectral region, such as $61 \mathrm{~cm}^{-1}$ $(1.8 \mathrm{THz}), 83 \mathrm{~cm}^{-1}(2.5 \mathrm{THz}), 101 \mathrm{~cm}^{-1}(3.0 \mathrm{THz}), 118 \mathrm{~cm}^{-1}(3.5 \mathrm{THz})$. Carli et al. (1989) and Carlotti et al. (2001) observed the 3.5 THz feature with a balloon-borne far infrared Fourier Transform spectrometer. Pickett and Peterson (1993) used a balloon-

25 borne two-channel (101 and $118 \mathrm{~cm}^{-1}$ ) Fabry-Perot instrument "FILOS" to retrieve stratospheric $\mathrm{OH}$, and middle to upper stratospheric $\mathrm{OH}$ concentrations were estimated from thermal emission far infrared $\left(83-230 \mathrm{~cm}^{-1}\right)$ observations with the balloon-borne "FIRS" Fourier transform spectrometer (Jucks et al., 1998). In August 1997, the airborne heterodyne spectrometer THOMAS performed $\mathrm{OH}$ observations between about 
30 and $90 \mathrm{~km}$ over a full diurnal cycle (Englert et al., 2000). The characterization of $\mathrm{OH}$ diurnal variability in the stratosphere and mesosphere has also been analyzed using measurements from the Aura/MLS instrument (Minschwaner et al., 2011). Both instruments observe $\mathrm{OH}$ at $2.5 \mathrm{THz}$, whereas TELIS selected $1.8 \mathrm{THz}$ for monitoring $\mathrm{OH}$ in

5 the lower and middle stratosphere. Although the $\mathrm{OH}$ emission at $1.8 \mathrm{THz}$ is weaker than that at $2.5 \mathrm{THz}$, the former one was chosen for the sake of higher sensitivity of the HEB (Hot Electron Bolometer) mixer at $1.8 \mathrm{THz}$ and risks associated with the development of the $2.5 \mathrm{THz}$ solid state local oscillator (Mair et al., 2004).

For being able to analyze the TELIS (or further spaceborne, e.g. SMILES, 10 Odin/SMR) measurements and retrieve trace gas profiles, the Remote Sensing Technology Institute at DLR has developed a retrieval code PILS (Profile Inversion for Limb Sounding) dedicated to high resolution infrared/microwave radiative transfer calculation and reliable inversion scheme. In this paper, we present the physical and mathematical basics of PILS as well as its capability of trace gas retrievals from synthetic TELIS

15 measurements. Particular emphasis is placed on the capability study of the $1.8 \mathrm{THz}$ channel. For a study of the $480-650 \mathrm{GHz}$ channel we refer to de Lange et al. (2009). The forward model used to simulate the measurements and the inversion methodology with diagnostics are described in Sect. 2. In Sect. 3 we firstly discuss the performance of $\mathrm{OH}$ vertical profile retrieval from a single limb scan with perfect instrumental knowledge. A sensitivity analysis is then conducted to estimate the impact of uncertainties in calibration procedure, the atmospheric and instrument parameters in the forward model. Section 4 identifies the capability of multi-channel simultaneous processing by implementing $\mathrm{HCl}$ retrieval. A summary and an outlook to future work and products are given in Sect. 5.

\section{Forward model and inversion methodology}

\subsection{Radiative transfer and instrument modelling}

In atmospheric remote sensing, the radiation seen by a sensor is described by the theory of radiative transfer with an appropriate instrument model, accounting for spectral 5 response, field-of-view, and - in case of heterodyne - the sideband ratio. Neglecting scattering and assuming local thermodynamical equilibrium, the intensity (radiance) I at wavenumber $v$ at position $s$ along the line-of-sight is given by the integral form of the Schwarzschild equation (Liou, 2002; Zdunkowski et al., 2007)

$I(v, s)=I\left(v, s_{0}\right) \mathrm{e}^{-\tau\left(v ; s_{0}, s\right)}+\int_{s_{0}}^{s} \mathrm{~d} s^{\prime} B\left(v, T\left(s^{\prime}\right)\right) \mathrm{e}^{-\tau\left(v ; s^{\prime}, s\right)} \alpha\left(v, s^{\prime}\right)$,

10 where $I\left(v, s_{0}\right)$ is the source radiation at position $s_{0}$, and $B(v, T)$ represents the Planck function at temperature $T$. The optical depth $\tau$ is defined as the path integral of the volume absorption coefficient $\alpha(v, s)$ which is essentially the product of molecular cross section $k$ and number density summed over the molecule. For high resolution a lineby-line evaluation is considered, i.e. $k$ is computed by summing over the contributions

15 from many lines: $k(v ; p, T)=\sum_{1} S_{1}(T) g\left(v ; \hat{v}_{1}, \gamma_{1}(p, T)\right)$, where each line is characterized by its position $\hat{v}_{\mid}$, the temperature-dependent line strength $S(T)$, and a Voigt line shape function $g$ (with half width $\gamma$ ) describing the combined effect of pressure $(p)$ broadening and Doppler broadening.

The subsequent step is to model the instrument performance as precisely as pos20 sible. For the $1.8 \mathrm{THz}$ channel, the monochromatic spectrum is convolved with an instrumental line shape function yielded by Fourier transform of a Hamming apodization function. For the $480-650 \mathrm{GHz}$ channel, a Lorentzian line shape function defined by the frequency locking (de Lange et al., 2009) is used. Moreover, a superposition of pencil-beam spectra can be done by convolving with an angle-dependent field-of-view 25 function which is Gaussian shaped with a vertical full width half maximum (FWHM) of 
$0.1043 \mathrm{deg}$ (6.3 arcmin) in the 1.8 THz channel (Suttiwong, 2010). The field-of-view at $619.1 \mathrm{GHz}$ is a Gaussian curve with a FWHM of $0.1805 \mathrm{deg}$ (10.8 arcmin).

For TELIS measurements, the measured spectrum is the weighted superposition of the spectra of the two sidebands by the sideband ratio. Ideally the sideband ratio $r$ is

5 equal to one, that is to say, both sidebands offer equal gain response. In Sect. 3.3.2 the effect of deviations in the sideband ratio from unity on retrieval results will be addressed.

\subsection{Inversion scheme and regularization}

The discretization of the radiative transfer equation leads to the nonlinear data model ${ }_{10} \boldsymbol{y}^{\delta}=\boldsymbol{F}(\boldsymbol{x})+\boldsymbol{\delta}$, where the mapping $\boldsymbol{F}: \mathbb{R}^{n} \rightarrow \mathbb{R}^{m}$ represents the forward model, $\boldsymbol{x} \in \mathbb{R}^{n}$ is the state vector, $\boldsymbol{y}^{\delta} \in \mathbb{R}^{m}$ is the noisy data vector, and $\boldsymbol{\delta} \in \mathbb{R}^{m}$ is the measurement error. The state vector comprises the atmospheric parameters to be retrieved, while the data vector is a concatenation of all limb spectra (Carlotti, 1988). Our analysis considers a semi-stochastic data model in the sense that the true solution $\boldsymbol{x}_{\mathrm{t}}$ is deterministic,

15 but the measurement error $\boldsymbol{\delta}$ is stochastic with zero mean and the noise covariance matrix $\mathbf{S}_{\delta}=\varepsilon\left\{\boldsymbol{\delta} \cdot \boldsymbol{\delta}^{T}\right\}=\sigma^{2} \mathbf{I}_{m}$, where $\mathcal{E}$ is the expected value operator, $\sigma^{2}$ is the noise variance, and $\mathbf{I}_{m}$ is the identity matrix in $\mathbb{R}^{m}$.

The inverse problem is ill-posed and a regularization method shall be used in order to obtain a solution with physical meaning. Tikhonov regularization (Tikhonov, 1963)

20 is a direct regularization method, in which the regularized solution $\boldsymbol{x}_{\lambda}$ minimizes the objective function

$$
\begin{aligned}
\mathcal{F}(x) & =\left\|F(x)-y^{\delta}\right\|^{2}+\lambda\left\|\mathbf{L}\left(x-x_{\mathrm{a}}\right)\right\|^{2} \\
& =\left\|\begin{array}{c}
F(x)-y^{\delta} \\
\sqrt{\lambda} \mathbf{L}\left(x-x_{\mathrm{a}}\right)
\end{array}\right\|^{2},
\end{aligned}
$$

where $\mathbf{L}, \lambda$, and $\boldsymbol{x}_{\mathrm{a}}$ represent the regularization matrix, the regularization parameter, and the a priori state vector, respectively. The regularization matrix, which encapsulates 257

our a priori knowledge about the solution, is chosen as the Cholesky factor of an a priori profile covariance matrix $\mathbf{S}_{\mathrm{x}}$, corresponding to an exponential correlation function, i.e. $\mathbf{S}_{\mathbf{x}}^{-1}=\mathbf{L}^{T} \mathbf{L}$, where

$$
\left[\mathbf{S}_{\mathbf{x}}\right]_{i j}=\left[\boldsymbol{x}_{\mathrm{a}}\right]_{i}\left[\boldsymbol{x}_{\mathrm{a}}\right]_{j} \exp \left(-2 \frac{\left|z_{i}-z_{j}\right|}{l_{i}+l_{j}}\right)
$$

5 with $i, j=1, \ldots, n$, and the lengths $I_{i}$ determine the correlation between the atmospheric parameters at different altitudes $z_{i}$. Note that for an equidistant altitude grid and $l_{i}=I$ for all $i=1, \ldots, n$, we have $\mathbf{L} \rightarrow \mathbf{I}_{n}$ as $I \rightarrow 0$, and $\mathbf{L} \rightarrow \mathbf{L}_{1}$ as $/ \rightarrow \infty$, where $\mathbf{L}_{1}$ is the discrete approximation to the first-order derivative operator. The proper selection of the regularization parameter $\lambda$ is critical, since the regularized solution should reflect a 10 trade off between the residual $\left\|\boldsymbol{F}(\boldsymbol{x})-\boldsymbol{y}^{\delta}\right\|^{2}$ and the penalty term $\left\|\mathrm{L}\left(\boldsymbol{x}-\boldsymbol{x}_{\mathrm{a}}\right)\right\|^{2}$. In this study, a priori parameter choice methods (Doicu et al., 2010) are applied to determine the regularization parameter.

Another widely-used so-called optimal estimation method (Rodgers, 2000) can be regarded as a stochastic version of Tikhonov regularization, in which the regularization

15 parameter is incorporated into the a priori profile covariance matrix, that is, $\mathbf{S}_{x}^{-1}=\lambda \mathbf{L}^{T} \mathbf{L}$. In this case, a trade off between the measurement and the a priori profile requires a proper selection of $\mathbf{S}_{\mathrm{x}}$. Furthermore, the optimal estimation method is more sensitive to the choice of a priori profile than Tikhonov regularization. In view of those target species lacking a priori knowledge, the retrieval with Tikhonov regularization can be 20 less influenced by the inadequate a priori information.

Numerical experience shows that the Tikhonov function in Eq. (2) usually has many local minima and a descent method for solving the optimization problem tends to get stuck especially for severely ill-posed problems. In this case, iterative regularization methods are an attractive alternative: the number of iteration steps plays the role of the regularization parameters, and the iterative process is stopped after an appropriate number of steps in order to avoid an uncontrolled amplification of the noise error. An intercomparison between Tikhonov regularization and two iterative methods will 
be given in Sect. 3.2. In the iteratively regularized Gauss-Newton method (Bakushinskii, 1992), the regularization parameters are the terms of a geometric sequence, i.e. $\lambda_{k}=q \lambda_{k-1}$, for some $q<1$, and the stopping index is chosen according to the discrepancy principle in dependence of the noise level and the noisy data vector. The

5 regularizing Levenberg-Marquardt method also uses a decreasing sequence of regularization parameters, but the penalty term depends on the previous iterate instead of the a priori.

Frequently the inversion deals with the joint retrieval of several concentration profiles corresponding to different molecules, and solves the underlying multi-component prob-

- lem by means of regularization. If the vector $\boldsymbol{x}_{p}$ comprises the concentration profile of the $p$ th molecule, then the state vector $\boldsymbol{x}$ is a concatenation of all $\boldsymbol{x}_{p}$. Assuming that the components of the state vector are independent, all individual regularization matrices $\mathbf{L}_{p}$ are assembled into a global regularization matrix $\mathbf{L}$ with a block-diagonal structure:

$\mathbf{L}=\left[\begin{array}{cccc}\sqrt{\lambda_{1}} \mathbf{L}_{1} & 0 & \cdots & 0 \\ 0 & \sqrt{\lambda_{2}} \mathbf{L}_{2} & \cdots & 0 \\ \vdots & \vdots & \ddots & \vdots \\ 0 & 0 & \cdots & \sqrt{\lambda_{N}} \mathbf{L}_{N}\end{array}\right]$

15 where $N$ is the number of gas components. Multi-parameter regularization methods can be classified according to the goal of the inversion process. The regularization parameters $\lambda_{k}$ are determined by minimizing certain objective functions corresponding to the entire state vector or to the main component of the state vector, respectively (Doicu et al., 2010).

$20 \quad 2.3$ Inversion diagnostics

A sensitivity analysis reveals our expectation on the inversion process. The sensitivity of the forward model with respect to components of the state vector is described in terms of the Jacobian matrix $\mathbf{K}=\partial F / \partial \boldsymbol{x}$. More precisely, for a change in the $k$ th 259

component of the state vector about the a priori, $\Delta \boldsymbol{x}_{k}=\boldsymbol{x}-\boldsymbol{x}_{\mathrm{a}}$, with $\left[\Delta \boldsymbol{x}_{k}\right]_{j}=\varepsilon\left[\boldsymbol{x}_{\mathrm{a}}\right]_{k}$ for $j=k$, and $\left[\Delta \boldsymbol{x}_{k}\right]_{j}=0$ for $j \neq k$, the change in the forward model is given componentwise by $\left[\Delta \boldsymbol{F}_{k}\right]_{i}=\varepsilon\left[\mathbf{K}\left(\boldsymbol{x}_{\mathrm{a}}\right)\right]_{i k}\left[\boldsymbol{x}_{\mathrm{a}}\right]_{k}$ with $i=1, \ldots, m$. In this context, one can say that the instrument is sensitive over the "entire" spectral domain to a $\pm \varepsilon$-variation in the $k$ th 5 component of the state vector about the a priori, if $\left|\left[\Delta F_{k}\right]_{j}\right|>\sigma$ for all $i=1, \ldots, m$.

The quality of the regularized solution can be assessed through an error analysis. By defining the regularized generalized inverse (also known as the gain matrix) $\mathbf{K}^{\dagger}=$ $\left(\mathbf{K}^{T} \mathbf{K}+\lambda \mathbf{L}^{T} \mathbf{L}\right)^{-1} \mathbf{K}^{T}$ and neglecting the higher-order terms of the solution, the retrieval error can be expressed as

$10 \boldsymbol{e}_{\lambda}=\boldsymbol{X}_{\lambda}-\boldsymbol{X}_{\mathrm{t}}=\boldsymbol{e}_{\mathrm{s}}+\boldsymbol{e}_{\mathrm{y}}+\boldsymbol{e}_{\mathrm{b}}$,

where $\boldsymbol{e}_{\mathrm{S}}=\left(\mathbf{A}-\mathrm{I}_{n}\right)\left(\boldsymbol{x}_{\mathrm{t}}-\boldsymbol{x}_{\mathrm{a}}\right)$ is the smoothing error that quantifies the loss of information due to the regularization, $\boldsymbol{e}_{\mathrm{y}}=\mathbf{K}^{\dagger} \boldsymbol{\delta}$ is the noise error that quantifies the loss of information due to the measurement noise $\boldsymbol{\delta}$, and $\boldsymbol{e}_{\mathrm{b}}=\mathbf{K}^{\dagger} \boldsymbol{\delta}_{\mathrm{b}}$ is the model parameter error. Here, $\mathbf{A}=\mathbf{K}^{\dagger} \mathbf{K}$ is the averaging kernel matrix and $\boldsymbol{\delta}_{\mathrm{b}}$ is the forward model

15 error. The smoothing error is not a computable quantity, but it can be estimated by $\boldsymbol{e}_{\mathrm{s}} \approx\left(\mathbf{A}-\mathbf{I}_{n}\right)\left(\boldsymbol{x}_{\lambda}-\boldsymbol{x}_{\mathrm{a}}\right)$. In a semi-stochastic setting, the smoothing and the model parameter errors are likely to be deterministic, while the noise error is stochastic with zero mean and covariance matrix. The model parameter error is caused by an inaccurate knowledge of the atmospheric and instrument parameters $\boldsymbol{b}$ employed in the forward 20 model. If $\Delta \boldsymbol{b}$ comprises the uncertainties in $\boldsymbol{b}$, then the forward model error can be computed as

$\delta_{\mathrm{b}}=\mathrm{K}_{\mathrm{b}} \Delta \boldsymbol{b} \approx F\left(x_{\mathrm{t}}, \boldsymbol{b}+\Delta b\right)-F\left(x_{\mathrm{t}}, \boldsymbol{b}\right)$

with $\mathbf{K}_{\mathrm{b}}$ being the Jacobian matrix with respect to $\boldsymbol{b}$. The quality of the regularized solution is estimated through the mean square error matrix defined by

$\mathbf{S}_{\lambda}=\mathcal{E}\left\{\left(x_{\lambda}-x_{\mathrm{t}}\right)\left(x_{\lambda}-x_{\mathrm{t}}\right)^{T}\right\} \approx \mathbf{S}_{\mathrm{s}}+\mathbf{S}_{\mathrm{y}}+\mathbf{S}_{\mathrm{b}}$ 
with $\mathbf{S}_{\mathrm{s}}=\boldsymbol{e}_{\mathrm{s}} \boldsymbol{e}_{\mathrm{s}}^{T}, \mathbf{S}_{\mathrm{y}}=\sigma^{2} \mathbf{K}^{\dagger} \mathbf{K}^{\dagger T}$, and $\mathbf{S}_{\mathrm{b}}=\boldsymbol{e}_{\mathrm{b}} \boldsymbol{e}_{\mathrm{b}}^{T}$.

\subsection{Implementation}

The forward model of PILS is one of the variants of GARLIC (Generic Atmospheric Radiation Line-by-line Infrared Code), a modern Fortran reimplementation of MIRART

5 (Modular InfraRed Atmospheric Radiative Transfer) (Schreier and Schimpf, 2001; Schreier and Böttger, 2003). GARLIC/MIRART is designed for arbitrary observation geometry (limb, nadir, up-looking) and instrumental line shape and field-of-view. For optimized line-by-line computations a combination of rational approximations for the Voigt line shape (Schreier, 2011) and a multigrid approach (Schreier, 2006) is implemented. MIRART has been verified in extensive intercomparisons (e.g. von Clarmann et al., 2002; Melsheimer et al., 2005). Besides, Hedelt et al. (2011) used MIRART to model observations of the Venus transit in 2004. Mendrok et al. (2007) and Vasquez et al. (2013) have introduced multiple/single scattering to estimate cirrus cloud parameters from MIPAS data and to model SCIAMACHY's Venus observations, respectively.

15 Efficient yet accurate computation of the Jacobian $\mathbf{K}$ is crucial for the solution of (constrained) nonlinear least squares problems. Although derivatives are straightforward to evaluate, a manual implementation is tedious and error prone; on the other hand, finite differences are extremely time consuming and unreliable because the appropriate perturbation is difficult to estimate. Surprisingly automatic or algorithmic differentia-

20 tion (AD) (Griewank, 2000) is rarely used in atmospheric remote sensing although a variety of tools (for Fortran, $\mathrm{C} / \mathrm{C}++$, etc.) have been developed in the past decades, see http://www.autodiff.org/. Schreier and Schimpf (2001); Schreier and Böttger (2003) used ADIFOR (Bischof et al., 1998) to implement derivatives in the Fortran 77 MIRART code utilizing source-code transformation and Ungermann (Ungermann et al., 2011) 25 introduced derivative code in JURASSIC2 (Jülich Rapid Spectral Simulation Code Version 2) by overloading in $\mathrm{C}++$ employing $\mathrm{DCO} / \mathrm{C}++$. PILS utilizes the source-to-source AD tool TAPENADE (Hascoët and Pascual, 2013) (version 3.4) to generate derivatives

in forward (tangent) mode, and the total computation time for all spectra comprising an entire limb sequence of 10 tangent altitudes plus Jacobians for 23 altitude levels is increased by just a factor of 2 in contrast to the pure forward calculation. For a discussion of the pros and cons of the various $A D$ techniques see, e.g. Bischof and Bücker 5 (2000).

The evaluation of the augmented vector in Eq. (3) relies on the use of optimization solver in the PORT Mathematical Subroutine Library (Fox et al., 1978, available at http://www.netlib.org/port/). The solver uses a trust-region method in conjunction with a Gauss-Newton model and a quasi-Newton model (Dennis Jr. et al., 1981). After 10 convergence, PILS delivers the diagnostic quantities introduced in Sect. 2.3, including the relative difference with respect to the true profile and the retrieval error (the square root of the diagonal elements of the mean square error matrix $\mathbf{S}_{\lambda}$ ).

\section{$3 \mathrm{OH}$ retrieval from the $1.8 \mathrm{THz}$ channel}

\subsection{Retrieval setup}

15 In order to explore the inversion performance and potential error sources, a set of numerical simulations has been made. We retrieve $\mathrm{OH}$ from a single limb-scanning sequence that largely resembles typical TELIS observations of the $1.8 \mathrm{THz}$ channel. The limb tangent altitude varies from 15 to $33 \mathrm{~km}$ in steps of $2 \mathrm{~km}$, and the observing altitude is set to $35 \mathrm{~km}$ (the dotted maroon horizontal line in the figures). The major in-

20 strument and geometry parameters used for simulating the synthetic spectra are listed in Table 1.

$\mathrm{H}_{2} \mathrm{O}, \mathrm{O}_{3}, \mathrm{HCl}, \mathrm{HOCl}$, and $\mathrm{HO}_{2}$ have been included in the simulation as the interfering molecules. The line parameters were read from the HITRAN 2008 (Rothman et al., 2009) spectroscopic database, and the semi-empirical Clough-Kneizys-Davis

25 (CKD) (Clough et al., 1989) model was used to account for the $\mathrm{H}_{2} \mathrm{O}$ continuum. It is important to choose a proper spectral microwindow covering targeted $\mathrm{OH}$ lines with 
minimum overlapped contributions from other atmospheric spectral lines. Here the LO frequency is set to $1830.10 \mathrm{GHz}\left(\approx 61.04 \mathrm{~cm}^{-1}\right)$ with an intermediate frequency range of $4-6 \mathrm{GHz}$, as employed during the campaigns in 2009 and 2011. The atmospheric pressure, temperature and molecular concentration profiles were taken from the AFGL

5 subarctic winter reference model (Anderson et al., 1986). The retrieval was performed on an altitude grid with a step of $2 \mathrm{~km}$ between 15 and $25 \mathrm{~km}$, a step of 2.5 between 25 and $50 \mathrm{~km}$, and a step of $5 \mathrm{~km}$ between 50 and $85 \mathrm{~km}$. Typical spectra are depicted in Fig. 1 for this $\mathrm{OH}$ microwindow.

The Jacobian matrices with respect to the molecular concentrations for a tangent

10 altitude of $25 \mathrm{~km}$ are plotted in Fig. 2 (the derivatives above $45 \mathrm{~km}$ are not shown here). In the derivative spectra of $\mathrm{OH}$, two triplet pairs are visible at both sides of the intermediate frequency point of about $4.65 \mathrm{GHz}$. It should be noticed that the strong triplet occurs in the upper sideband while the weaker one lies in the lower sideband. Both peaks are found to be larger than the middle trough with a factor of 1.5 and the peaks 15 are about two to five orders of magnitude larger than those of the other molecules.

A sequence of noise contaminated spectra is essential for realistic inversion analysis. In the present simulations only the radiometric noise was considered. The signal-tonoise ratio (SNR) for a single spectrum can be estimated by

$\mathrm{SNR}=\frac{T_{\text {sig }}}{T_{\text {sys }}} \sqrt{\Delta f t}$,

20 where the TELIS spectral resolution $\Delta f$ is $2.16 \mathrm{MHz}$, and the integration time $t$ is $1.5 \mathrm{~s}$. For the $1.8 \mathrm{THz}$ channel the average system noise temperature ranges between 3000 and $4000 \mathrm{~K}$ (Birk et al., 2010). In case of the selected $\mathrm{OH}$ microwindow, the system noise temperature $T_{\text {sys }}$ can reach $3800 \mathrm{~K}$. According to Fig. 1, the equivalent brightness temperatures of the $\mathrm{OH}$ emission line $T_{\text {sig }}$ are above $75 \mathrm{~K}$, which causes the lowest

25 signal-to-noise ratio of $\mathrm{SNR} \approx 35$. The worst-case scenario was used to conduct the retrieval feasibility study. The noise $\delta$, which is added to the noise-free spectrum for

each tangent altitude, is described by a Gaussian distribution. There is no correlation in terms of the added noise over the frequency range.

\subsection{Retrieval results}

In this subsection, temperature, pressure, $\mathrm{HCl}, \mathrm{HOCl}, \mathrm{HO}_{2}$ were assumed to be known 5 and set to their a priori values. Perfect atmospheric and instrument parameters were assumed in the forward model so that $\boldsymbol{e}_{\mathrm{b}}=0$. The initial guess and a priori profile of the target molecule(s) $x_{0}$ and $x_{\mathrm{a}}$, respectively, were assumed to be identical and chosen as

$x_{0}=x_{\mathrm{a}}= \begin{cases}0.1 x_{\mathrm{t}} & \text { if } z<30 \mathrm{~km} \\ 0.12 x_{\mathrm{t}} & \text { if } z \geq 30 \mathrm{~km}\end{cases}$

10 A sensitivity study involving the variations of the limb radiances $\Delta \boldsymbol{F}_{k}^{S}$, corresponding to the sth tangent height and to a $10 \%$ variation of the concentration profile of relevant molecules in the $k$ th level is illustrated in Fig. 3. The results show that information about the concentration profile in a specific level is mainly given by the spectra corresponding to the tangent heights below the altitude level (see also Fig. 2). The instrument is

15 sensitive to $\mathrm{OH}$ in the frequency range of $4.5-5 \mathrm{GHz}$. In this spectral range and for altitude levels above $27.5 \mathrm{~km}$, the sensitivity of $\mathrm{OH}$ is superior to that of other molecules. Below $27.5 \mathrm{~km}$, the $\mathrm{OH}$ concentration is rather low and of no significant importance for the measured radiance signal. In this regard, it can be expected that the retrieval of $\mathrm{OH}$ at altitude levels below $27.5 \mathrm{~km}$ is essentially based on the a priori information and not

20 from the measurement. For the $\mathrm{OH}$ retrieval problem, the variations of the spectra at 27.5 and $30 \mathrm{~km}$ are not substantially larger than the noise level, that can imply a worse noise error below $30 \mathrm{~km}$. 


\subsubsection{One-profile retrieval}

First of all, we consider only $\mathrm{OH}$ as target molecule (with accurate a priori knowledge of $\mathrm{O}_{3}$ and $\mathrm{H}_{2} \mathrm{O}$ ) to clarify the retrieval capability of the selected microwindow. The estimation of an appropriate regularization parameter plays an important role in finding

5 a reliable retrieval solution. For this purpose, we solve the one-profile retrieval problem for various regularization parameters $\lambda$, and for each $\lambda$ the relative solution errors $\epsilon(\lambda)=\left\|\boldsymbol{x}_{\lambda}-\boldsymbol{X}_{\mathrm{t}}\right\| /\left\|\boldsymbol{x}_{\mathrm{t}}\right\|$ are computed. In Fig. 4a we illustrate the relative solution errors of $\mathrm{OH}$ volume mixing ratio (VMR) for Tikhonov regularization, the iteratively regularized Gauss-Newton method, and the regularizing Levenberg-Marquardt method. For

10 iterative methods, $\lambda$ is the initial value of the regularization parameter, while at all subsequent iteration steps, the regularization parameters are the terms of a geometric sequence with the ratio $q=0.8$. The error curve corresponding to Tikhonov regularization possesses a minimum, and by convention, the minimizers of the solution errors represent the optimal values of the regularization parameter.

15 Still the iteratively regularized Gauss-Newton method yields reliable results for large initial values of the regularization parameter. Evidently, a stronger regularization at the beginning of the iterative process requires a larger number of iterations as can be seen in Fig. 4b. The regularizing Levenberg-Marquardt method is also insensitive to overestimations of the regularization parameter. However, the results in Fig. 4 illustrate that

20 the regularizing Levenberg-Marquardt method is inferior to the iteratively regularized Gauss-Newton method: for large initial values of the regularization parameter, the solution errors are larger. Henceforth, we choose Tikhonov regularization essentially for efficiency reasons as it converges quickly (with $\leq 5$ iteration steps) disregarding any choice of $\lambda$.

25 For $\lambda=1 \times 10^{-4}$, the retrieved $\mathrm{OH}$ concentration profile along with the corresponding quantity in terms of relative difference is plotted in Fig. $5 \mathrm{a}$. The relative difference is up to $12 \%$ (at $15 \mathrm{~km}$ ) in the plotted altitude range. The quality of the retrieval is also assessed by the retrieval error encapsulating the combined effect of the noise and the

smoothing errors (Fig. 5b). The smoothing error dominates the retrieval error budget from 15 to $27.5 \mathrm{~km}$ where the noise error is fairly small, which implies that the retrieval error at these altitudes relies on the a priori information and the vertical resolution is poor. The noise error as the main error stretches from $27.5 \mathrm{~km}$ upward, while the 5 smoothing error appears to take less effect.

\subsubsection{Two-profile retrieval}

For the two-profile retrieval we consider a joint retrieval of $\mathrm{OH}$ and $\mathrm{O}_{3}$. For multi-profile retrieval a smaller spectral window of $500 \mathrm{MHz}$, corresponding to the second autocorrelator segment of $4.5-5 \mathrm{GHz}$, is used. Based on the previous sensitivity analysis, the sensitivity of $\mathrm{OH}$ is highest in this spectral range. In Fig. 1 a pair of strong $\mathrm{O}_{3}$ lines appears in the wings of the $\mathrm{OH}$ triplet, which implies that an uncertainty in the concentration profile of $\mathrm{O}_{3}$ may have a distinct influence on the retrieval results of $\mathrm{OH}$. To investigate how well $\mathrm{OH}$ can be retrieved without an accurate a priori knowledge of ozone, $\mathrm{O}_{3}$ is retrieved simultaneously with $\mathrm{OH}$.

For the joint retrieval of $\mathrm{OH}$ and $\mathrm{O}_{3}$ we minimize (2) in conjunction with Eq. (5) for a set of regularization parameters $\lambda=\left(\lambda_{\mathrm{OH}_{1}}, \lambda_{\mathrm{O}_{3}}\right)$, and then compute the solution errors in each component, that is, $\epsilon_{\mathrm{OH}}(\lambda)=\left\|x_{\mathrm{OH}, \lambda}-x_{\mathrm{OH}, t}\right\| /\left\|x_{\mathrm{OH}, \mathrm{t}}\right\|$ and $\epsilon_{\mathrm{O}_{3}}(\lambda)=$ $\left\|x_{\mathrm{O}_{3}, \lambda}-x_{\mathrm{O}_{3}, t}\right\| /\left\|x_{\mathrm{O}_{3}, t}\right\|$, as well as the total solution error $\epsilon(\lambda)=\sqrt{\epsilon_{\mathrm{OH}}(\lambda)^{2}+\epsilon_{\mathrm{O}_{3}}(\lambda)^{2}}$. The results in Fig. 6 show that for $\lambda_{\mathrm{OH}}=1 \times 10^{-4}$ and $\lambda_{\mathrm{O}_{3}}$ ranging between $1 \times 10^{-6}$ and 1 , the total solution error is small and almost constant. However, in order to obtain smaller residual after convergence, the regularization parameters of $\mathrm{OH}$ and $\mathrm{O}_{3}$ are set to $\lambda_{\mathrm{OH}}=1 \times 10^{-4}$ and $\lambda_{\mathrm{O}_{3}}=1 \times 10^{-6}$, respectively.

The relative differences of $\mathrm{OH}$ and $\mathrm{O}_{3}$ are displayed in the left panel (a) of Fig. 7. Although $\mathrm{O}_{3}$ is weakly regularized during the retrieval, an error of less than $5 \%$ is 25 found below the observing altitude, however, an underestimate above $35 \mathrm{~km}$ can be observed. Concerning $\mathrm{OH}$, errors of less than $15 \%$ with respect to the true profile in 
both combinations are observed over the whole altitude range, that are comparable to the result of the one-profile fit. The right panel (b) of Fig. 7 illustrates the retrieval error, the smoothing and the noise errors for the retrieved molecules. The retrieval error is dominated by the smoothing error at lower altitudes and by the noise error above

$525 \mathrm{~km}$. It is apparent that the vertical resolution of the retrieval of $\mathrm{OH}$ is poorer than the $\mathrm{O}_{3}$ retrieval. The smoothing error of $\mathrm{O}_{3}$ is very small, which reveals that the main information comes from the measurement itself rather than from the a priori information.

\subsubsection{Three-profile retrieval}

Another aspect to consider is the three-profile retrieval. The state vector comprises 10 three molecules, i.e. $\mathrm{OH}, \mathrm{O}_{3}$, and $\mathrm{H}_{2} \mathrm{O}$. The same spectral window as the two-profile retrieval is used. The regularization parameters $\lambda_{\mathrm{OH}}=1 \times 10^{-4}, \lambda_{\mathrm{O}_{3}}=2 \times 10^{-6}$, and $\lambda_{\mathrm{H}_{2} \mathrm{O}}=5 \times 10^{-6}$ have been chosen by using the technique described in Sect. 3.2.2.

The difference with respect to the true profile in Fig. 8a shows that the $\mathrm{OH}$ retrieval can be done over the whole altitude range, although the errors are slightly larger than

15 for the single- and two-profile retrievals. It may suggest that the inaccurate a priori knowledge of $\mathrm{H}_{2} \mathrm{O}$ and $\mathrm{O}_{3}$ could influence the $\mathrm{OH}$ retrieval. The retrieval error of $\mathrm{OH}$ in Fig. $8 \mathrm{~b}$ is quite similar to the results above.

Using synthetic noisy measurements based on the perfect instrumental knowledge, the vertical concentration profile of $\mathrm{OH}$ can be retrieved in both single- and multi-profile

20 retrieval frameworks in decent quality. A priori knowledge affects the retrieval error and yields a poor vertical resolution at lower altitudes, while the noise error dominates the retrieval error budget at higher altitudes. Although the spectral information over the instrument is limited, the profile of $\mathrm{OH}$ above $35 \mathrm{~km}$ can still be retrieved due to its high sensitivity in the middle stratosphere. Nonetheless, the imperfect instrumental

25 knowledge and inaccurate atmospheric parameters can degrade the quality of retrieved solution.

\subsection{Sensitivity to expected error sources}

In the retrieval results displayed above, several assumptions of forward model profiles and instrument parameters have been made. However, it is of importance to see how imperfect atmospheric state profiles and instrumental knowledge influence the per-

5 formance of the retrieval. For this reason, an error analysis has been carried out for atmospheric profiles and instrument parameters. In this study only the most important error sources (known from previous studies, e.g. de Lange et al., 2009, 2012; Baron et al., 2011; Urban et al., 2005) have been considered. As $\mathrm{O}_{3}$ appears to be important in this $\mathrm{OH}$ microwindow, $\mathrm{OH}$ and $\mathrm{O}_{3}$ were considered as the target molecules of

10 multi-profile fitting involved in the following simulations. The selected regularization parameters are $\lambda_{\mathrm{OH}}=1 \times 10^{-4}$ and $\lambda_{\mathrm{O}_{3}}=1 \times 10^{-6}$. In contrast to Sect. 3.2, the initial and a priori profiles of the target molecules were scaled with a factor of 0.1 , or rather, a priori error of $90 \% . \mathrm{H}_{2} \mathrm{O}, \mathrm{HCl}, \mathrm{HOCl}$, and $\mathrm{HO}_{2}$ were assumed to be known. In this study we concentrate on the performance of the $\mathrm{OH}$ retrieval affected by errors in calibration 15 procedure, instrumental knowledge and atmospheric profiles.

\subsubsection{Calibration error}

Radiometric accuracy is crucial for a good quality of atmospheric profiles retrieval, especially systematic radiometric errors can result in a bias in the retrieval. For TELIS, a linear radiometric calibration approach is employed. An on-board blackbody unit is 20 used as a hot signal reference and the signal from pointing into deep space is used as a cold signal reference. To reduce drift effects, both blackbodies are measured in short time intervals (ca. every $30 \mathrm{~s}$ ) between the limb scans. From these hot and cold calibration measurements, the unknowns of the instrument's response function, the radiometric gain and the offset, can be determined and thus allow for a linear radiometric

25 calibration of the measured spectra. However, in the TELIS IF-signal chain nonlinearities are present, which can not be compensated by the linear calibration approach and further lead to systematic errors in radiometric calibrated spectra. To study the 
influence of the nonlinearity on the retrieval, the linear calibration procedure together with a nonlinear instrument response needs to be modelled.

Assuming a linear response system, the instrument output $y^{i}$ for a given input signal $I_{\mathrm{m}}^{\mathrm{i}}$ can be given by

${ }_{5} y^{i}=G\left(I_{\mathrm{m}}^{\mathrm{i}}+I_{T_{\text {sys }}}\right)$, with $i=\mathrm{atm}, \mathrm{H}, \mathrm{C}$,

where $I_{\mathrm{m}}^{i}$ denotes a noise-free model spectrum with the index $i$ indicating an atmospheric (atm) spectrum, a hot load $(\mathrm{H})$ spectrum or a cold load $(\mathrm{C})$ spectrum. The offset $I_{T_{\text {sys }}}$ represents the modelled intensity of a blackbody at the system noise temperature of the heterodyne receiver and $G$ specifies the radiometric gain. In the linear calibration scheme, the unknowns of the instrument's response, the gain and the offset are then derived from calibration measurements of both known reference blackbodies with

$G=\frac{y^{H}-y^{C}}{I_{m}^{H}-I_{m}^{C}}$

and

${ }_{15} I_{T_{\text {sys }}}=\frac{I_{m}^{\mathrm{H}} y^{\mathrm{C}}-I_{\mathrm{m}}^{\mathrm{C}} y^{\mathrm{H}}}{y^{\mathrm{H}}-y^{\mathrm{C}}}$.

$I_{\mathrm{m}}^{\mathrm{H}}$ and $I_{\mathrm{m}}^{\mathrm{C}}$ are computed via Planck's law from given brightness temperatures of the hot and cold blackbodies. Consequently, the radiometric calibrated atmospheric spectrum $I_{\mathrm{cal}}^{\mathrm{atm}}$ can be calculated from the instrument output $y^{\text {atm }}$ using Eqs. (12) and (13):

$I_{\text {cal }}^{\text {atm }}=\frac{y^{\mathrm{atm}}}{G}-I_{T_{\text {sys }}}$.

However, according to on-ground characterizations of TELIS using gas cell measurements, the input-output relation of the instrument is nonlinear and therefore Eq. (11) does not hold. Although experiments show a complex combination of nonlinear elements in the IF-signal chain, a more generic approach is employed in this study. The 5 nonlinearities of the instrument can be approximated by an effective, quadratic nonlinearity, which is only sensitive to the integral power along the bandwidth $W$ at the input. As a result, Eq. (11) shall be reformulated as

$y_{\mathrm{nl}}^{i}=\left(I_{\mathrm{m}}^{i}+I_{T_{\text {sys }}}\right)\left(1+C_{\mathrm{nl}} \int_{W} \mathrm{~d} v\left(I_{\mathrm{m}}^{i}+I_{T_{\text {sys }}}\right)\right)$,

where $C_{\mathrm{nl}}$ is the coefficient which defines the quadratic nonlinearity. For the sake of 10 simplicity, the linear coefficient is set to one. As the nonlinearity is caused by saturation effects in the amplifier chain, $C_{\mathrm{nl}}<0$ applies. This leads to a compression $\omega$ of the output with respect to the linear case with $\omega=1-y_{\mathrm{nl}}^{i} / y^{i}<1$. To calculate the nonlinear outputs $y_{\mathrm{nl}}^{i}$, the quadratic coefficient $C_{\mathrm{nl}}$ is chosen such that the compression of the modelled hot load measurement $y_{\mathrm{n}}^{\mathrm{H}}$ is comparable to the values deduced from labora15 tory measurements. The nonlinearity is then propagated into the calibration procedure by replacing $y^{i}$ with $y_{\mathrm{nl}}^{i}$ in Eqs. (12)-(14).

The obtained calibrated spectra $I_{\text {cal }}^{\text {atm }}$, which are distorted by the nonlinearity, are compared with the pure atmospheric model spectra $I_{\mathrm{m}}^{\text {atm }}$ and then used as input for the retrieval. In case of the $\mathrm{OH}$ microwindow, the blackbodies having the temperature of 278 and $2.725 \mathrm{~K}$ are used as the hot and cold load, respectively. The compression in the hot load is estimated with $\omega=20 \pm 10 \%$. The modelled calibrated spectra an on tangent altitude are plotted in Fig. 9 and compressions of 10 and $30 \%$ are assumed for the nonlinearity. As can be seen from the residuals, the nonlinearity results in a line scaling effect in the calibrated spectra with respect to the ideal case.

25 Furthermore, the calibrated spectra with the compression of $30 \%$ were used as the worst-case scenario and the retrieval was performed with the noisy synthetic 
measurements distorted by the nonlinearity. It is expected that the retrieved profile of $\mathrm{OH}$ and $\mathrm{O}_{3}$ can be distorted resulting from the line scaling effect in the measurements. Thus, a pseudo-correction scheme for simulating the linear calibration procedure is implemented in the retrieval, which superimposes the nonlinearity onto the model spectra

5 by Eq. (14) at every iteration step with the given compression quantities $\omega$. The nonlinear outputs $y_{\mathrm{nl}}^{i}$ are evaluated by Eq. (15). The radiometric gain $G$ and the offset $I_{T_{\text {sys }}}$ in the nonlinear system are computed by Eqs. (12) and (13), respectively. To access the error propagation onto the retrieval products, an additional $5 \%$ uncertainty was assumed, i.e. the retrievals were repeated with the compression $\omega$ set to 25 and $35 \%$, respectively. The retrieval results of $\mathrm{OH}$ and $\mathrm{O}_{3}$ are compared to the results without the correction in Fig. 10. In this case, neither the noise errors nor the smoothing errors are increased in an evident way. Accordingly, the influence on the retrieval error is low (not shown). The errors in terms of relative difference imply that the nonlinearity effect is more severe on $\mathrm{O}_{3}$, that causes largest error of $20 \%$ at $15 \mathrm{~km}$. The retrieved $\mathrm{OH}$

15 profile is not affected by the nonlinearity below $21 \mathrm{~km}$ due to the fact that there is no strong $\mathrm{OH}$ signal below this altitude (see also Fig. 1). The results for correction with 25 and $35 \%$ compression are almost symmetric with respect to the case of $30 \%$ (above $25 \mathrm{~km}$ for $\mathrm{OH}$ ). As expected, the nonlinearity can affect the retrieval of $\mathrm{OH}$ at higher altitudes where the spectral feature is strong.

20 The nonlinearity effect has been studied with the modelled calibration procedure and the corresponding retrieval results from these measurements. The errors with respect to the true profile declare that the nonlinearity can bring about an error on the $\mathrm{OH}$ retrieval in the middle stratosphere where the $\mathrm{OH}$ lines are easily identifiable. With the pseudo-correction scheme applied to the retrieval, the errors with respect to the true 25 profile are reduced by up to $7 \%$, as can be inferred from Fig. 10.

\subsubsection{Instrumental knowledge: sideband ratio}

Uncertainties in the parameters used by the instrument module of the forward model might cause systematic biases in the retrieved vertical profiles. Excluding the 271

calibration error, the most important instrumental error sources for the TELIS observations are discussed below and in Sect. 3.3.3.

The precise knowledge of the receiver sideband ratio is a fundamental requirement for the calculation of the TELIS spectra. An error in the sideband ratio $r$ can result in 5 a systematic change in the contributions of the spectra, and further, an unexpected error in the retrieval results. We define the distorted sideband ratio as $\tilde{r}=r(1+\eta)$ by introducing a relative bias $\eta$, the measured spectrum $/$ is expressed as:

$$
\begin{aligned}
I & =\frac{r}{r+1} I_{\mathrm{USB}}+\frac{1}{r+1} I_{\mathrm{LSB}} \\
& =\frac{r}{r+1}\left(1+\frac{\eta}{r(1+\eta)+1}\right) I_{\mathrm{USB}}+\frac{1}{r+1}\left(1-\frac{r \eta}{r(1+\eta)+1}\right) I_{\mathrm{LSB}},
\end{aligned}
$$

10 where $I_{\text {USB }}$ and LSB $_{\text {LS }}$ denote the spectra of the upper sideband (USB) and lower sideband (LSB), respectively. The strong $\mathrm{OH}$ line lies in the upper sideband of the selected LO frequency in this study. A positive $\eta$ means an overestimated contribution of the upper sideband in the spectra, while a negative $\eta$ will lead to an underestimated intensity. To study the impact of the error in the sideband ratio, the relative bias $\eta$ has

15 been studied in the following simulation. According to recent laboratory measurements performed for characterization of the sideband ratio, $r$ is estimated to lie in the range of 0.95 to 1.05 for the $1.8 \mathrm{THz}$ channel, i.e. maximal uncertainty of $5 \%$ with respect to the ideal sideband ratio $r=1.0$. The values $\pm 0.01, \pm 0.03, \pm 0.05$, and \pm 0.1 (extreme case) for $\eta$ are taken into account. The propagated error on the retrieval has been eval20 uated by using the linear mapping $\left(\boldsymbol{e}_{\mathrm{b}}=\mathbf{K}^{\dagger} \boldsymbol{\delta}_{\mathrm{b}}\right.$ with Eq. (7)) which relates changes in the solution to changes in the spectra via $\mathbf{K}^{\dagger}$.

For all altitudes below the observing altitude of $35 \mathrm{~km}$, the bias $\eta(-0.1 \sim 0.1)$ in the sideband ratio produces the propagated error of less than $3 \%$ in the retrieved $\mathrm{O}_{3}$ profile (these results are not shown here). The propagated errors in the $\mathrm{OH}$ retrieval 25 are depicted in Fig. 11. The relative retrieval error and the noise error are also included for comparison. The errors introduced by the small biases $(0.01$ and 0.03$)$ can reach $5-15 \%$ at $21 \mathrm{~km}$ and decrease with increasing altitude. The results are found to be 
more severely influenced by larger biases (0.05 and 0.1$)$. For more clarity, the large sideband ratio bias can result in significant error on the retrieval quality of $\mathrm{OH}$.

In Fig. 12 the errors in terms of relative difference are obtained by retrievals with different $\eta$ in the sideband ratio. The measurement is for the assumed sideband ratio

$5 r=1.0 . \mathrm{O}_{3}$ is not plotted for the reason that no significant error on the retrieved profile is induced by the sideband ratio bias. In our case, the intensity is sensitive to the contribution of $\mathrm{OH}$ in the upper sideband. As judged from Eq. (16) and Fig. 11, the retrieved $\mathrm{OH}$ profile is overestimated with positive biases on the sideband ratio, whereas underestimated with negative ones.

\section{$10 \quad$ 3.3.3 Instrumental knowledge: pointing}

A pointing error can be characterized by systematic pointing bias and random pointing offset. The pointing error can be expressed by an altitude error at the tangent point, or by an error in the zenith angle of the line-of-sight. The MIPAS-B instrument on the gondola is equipped with a highly stable attitude and heading reference system (Friedl-

15 Vallon et al., 2004). Although TELIS also receives its pointing information from this system, the stability of the connection between both instruments remains to be examined, a fact which could have an impact on the quality of the trace gas retrieval. It has been probed that the systematic pointing bias is 3.4 arcmin on the zenith angle for the $1.8 \mathrm{THz}$ channel, corresponding to a $500 \mathrm{~m}$ deviation for the lowest tangent altitude $20 \quad(15 \mathrm{~km})$ in this case.

Assuming that the uncertainty in this systematic pointing bias is up to 1 arcmin, the expected error propagation onto the retrieved profile of $\mathrm{OH}$ is plotted in Fig. 13. As this bias is deterministic, the propagated error is estimated by using Eq. (7) in the framework of a linearized forward model about the true state. A propagated error of up

25 to $0.01 \mathrm{ppbv}$ with the uncertainty of 1 arcmin is found below the observing altitude. As a result of very low concentration at lower altitude, the largest propagated error occurs between $15-25 \mathrm{~km}$.

273

The relative differences in the $\mathrm{OH}$ profile for a single-target retrieval by assuming the uncertainties of 0.5 and 1 arcmin in the systematic pointing bias ( 3.4 arcmin) are shown in Fig. 14a. These results are in agreement with the relative propagated errors in Fig. 13b, leading to the conclusion that the forward model is not too nonlinear. The 5 pointing error yields a shift of all gas profiles. $\mathrm{As}_{3}$ is the most important contributor to the measurement signal, an unresolved shift of the $\mathrm{O}_{3}$ profile is the reason for the large relative differences in the $\mathrm{OH}$ profile. The relative differences in the $\mathrm{OH}$ profile become considerably smaller if a joint retrieval of $\mathrm{OH}$ and $\mathrm{O}_{3}$ is performed, as can be seen in Fig. 14b.

10 The standard approach for far infrared and microwave limb sounding is to extract the pointing information from measurements of oxygen emission lines. Alternatively, the pointing error can be retrieved for each spectrum in the limb sequence together with the target molecules. In this case the random pointing offset is nearly compensated.

\subsubsection{Atmospheric profiles}

15 The accuracy of the temperature profile is vital to the reliability of target gas retrievals. For more precise retrieval results from actual TELIS data, the MIPAS-B temperature retrieval can be a pleasant candidate due to the fact that MIPAS-B and TELIS are both carried by the same gondola frame.

We have assumed an uncertainty of $1 \mathrm{~K}$ on the temperature profile for altitudes up to

$2045 \mathrm{~km}$ to investigate the corresponding effect on the retrieval. In Fig. 15, the estimated error propagation onto the retrieved $\mathrm{OH}$ profile via Eq. (7) is depicted. Below $27.5 \mathrm{~km}$, the propagated error ranges $10-14 \%$. The profile is saturated and depleted by up to $0.0006 \mathrm{ppbv}$ respectively with errors of 1 and $-1 \mathrm{~K}$ in the temperature profile. Between 27.5 and $35 \mathrm{~km}$, a propagated error of up to $7 \%$ is found despite an increased absolute

25 propagated error because of up to two orders of magnitude higher concentration in the stratosphere. It implies that a slight deviation in the temperature profile may cause an error especially at lower altitudes (upper troposphere and lower stratosphere) where the concentration of $\mathrm{OH}$ is relatively low. 
Moreover, we have assessed the propagation of a pressure error onto the $\mathrm{OH}$ retrieval by introducing errors of -1 and $1 \%$ for the whole altitude grid. Compared to the error propagation by the temperature profile, the assumed errors on the pressure profile lead to considerable effects between 15 and $30 \mathrm{~km}$ (Fig. 15). A propagated error

5 of up to $0.006 \mathrm{ppbv}$ is found over the altitude range of $15-35 \mathrm{~km}$, where the largest value is located at the altitude of $21 \mathrm{~km}(56 \%)$. Below the observer, the profile is saturated with a positive error, while depleted with a negative error. $\mathrm{O}_{3}$ is not affected by the assumed errors on the pressure profile, the accuracy of the pressure profile is therefore of importance to retrieval of $\mathrm{OH}$ and other weak molecules.

For analysis of the real measurements, the pressure profile can be taken from the ECMWF (European Centre for Medium-Range Weather Forecasts) data. Alternatively, atmospheric pressure can be calculated from the temperature profile via the hydrostatic equation.

Regarding other interfering gases, inaccurate a priori knowledge of $\mathrm{HCl}$ and $\mathrm{HO}_{2}$ 15 does not affect the $\mathrm{OH}$ retrieval.

\section{Capability of multi-channel simultaneous retrieval}

During the flight, TELIS can measure two of three channels simultaneously. It is tempting to consider improving the retrieval accuracy by the simultaneous processing of several windows. Multi-window retrieval is commonly used for instruments covering broad

20 spectral bands, notably Fourier transform spectrometer, e.g. MIPAS (Fischer et al., 2008), whereas the synergistic analysis of spectra measured by different instruments is discussed in few papers only, e.g. IASI and GOME-2 (Landgraf and Hasekamp, 2007), or IASI and MIPAS (Ceccherini et al., 2010). Here a joint retrieval from far infrared and submillimeter observations offers a novel aspect (to our knowledge Aura/MLS does not

25 exploit the $\mathrm{GHz}$ and $\mathrm{THz}$ channels simultaneously). We focus on a combination of the 1.8 THz and $480-650 \mathrm{GHz}$ channels since both channels observe a number of common molecules, e.g. $\mathrm{HCl}, \mathrm{HOCl}, \mathrm{HO}_{2}, \mathrm{NO}, \mathrm{O}_{3}, \mathrm{H}_{2} \mathrm{O}$ and its isotopologues. In this study

$$
275
$$

we investigate the retrieval capability of $\mathrm{HCl}$ by multi-channel fitting. Note that these two channels are characterized by different spectral response functions.

Table 2 summarizes the main instrument and atmospheric parameters. TELIS can measure signals at different observing and tangent altitudes during the flight, a corre5 sponding change of geometry with respect to Table 1 has been made. The synthetic measurement is simulated for two $\mathrm{HCl}$ microwindows observed with the LO frequency set to 1877.63 and $619.10 \mathrm{GHz}$ as utilized during the previous flights. Random noise is superimposed onto the measurement for each channel with the estimated signal-tonoise ratio. In addition to the target molecule, $\mathrm{H}_{2} \mathrm{O}, \mathrm{O}_{3}, \mathrm{O}_{2}, \mathrm{NO}_{2}, \mathrm{ClO}$, and $\mathrm{HOCl}$ were taken as the interfering molecules.

The state vector is constructed from the VMR profiles of the main target $\mathrm{HCl}$ and one auxiliary molecule $\mathrm{O}_{3}$, with the a priori error of $90 \%$. The retrieval grid is discretized in $1.5 \mathrm{~km}$ between 10 and $32.5 \mathrm{~km}$ which is equivalent to the tangent spacing, and the same spacing above $32.5 \mathrm{~km}$ as in Sect. 3.1. In this section, the regularization parameters are estimated by minimizing certain objective functions corresponding to the main component of the state vector, i.e. the reconstruction of $\mathrm{HCl}$. All retrievals are performed with $\lambda_{\mathrm{HCl}}=1 \times 10^{-4}$ and $\lambda_{\mathrm{O}_{3}}=0$.

In Fig. 16a the averaging kernels for $\mathrm{HCl}$ retrieval using the multi-channel measurement are compared with those using only the single-channel measurement. The aver-

20 aging kernels for the multi-channel case indicate an improved vertical resolution below $20.5 \mathrm{~km}$ where the averaging kernels obtained from the measurement in the $\mathrm{THz}$ channel are rather wide. On the other hand, the averaging kernels for the multi-channel case below $20.5 \mathrm{~km}$ imply that the $\mathrm{GHz}$ channel data provides a better resolution of the retrieval product also over this altitude range. Above $20.5 \mathrm{~km}$ the averaging kernels for

25 the profile obtained from the multi-channel data are quite similar to those obtained from the $\mathrm{THz}$ channel measurement alone. A noticeable quality improvement in terms of the degree of freedom for signal is also obtained. By using both channels concurrently, the corresponding smoothing error (Fig. 16b) indicates that regularization results in less information loss below $22 \mathrm{~km}$ and the noise error below $19 \mathrm{~km}$ is decreased by about 
a factor of 5, as compared to the results using the $\mathrm{THz}$ channel only. In this case, the relative retrieval error is therefore $5-10 \%$ better over the altitude range of $10-20.5 \mathrm{~km}$. For the retrieval using the $\mathrm{THz}$ channel only, the noise error dominates the retrieval error over the whole altitude range due to the worse signal-noise-ratio, whereas the noise

5 error is very closed to zero for the retrieval with the $\mathrm{GHz}$ channel data. The smoothing error for all retrievals is large below $20.5 \mathrm{~km}$ and the regularization can have an effect on the retrieval quality of $\mathrm{HCl}$. By comparison with the results using the $\mathrm{GHz}$ channel alone, a smaller smoothing error given by the multi-channel measurement is achieved, although a slightly worse retrieval error is found above $20.5 \mathrm{~km}$ due to larger measure-

10 ment noise in the $\mathrm{THz}$ channel. According to these results, the sensitivity of $\mathrm{HCl}$ in the $\mathrm{THz}$ channel microwindow is superior to that in the $\mathrm{GHz}$ channel microwindow at higher altitudes, while at lower altitudes the $\mathrm{GHz}$ channel data delivers a stronger $\mathrm{HCl}$ signal.

In Fig. 17 the errors of $\mathrm{HCl}$ with respect to the true profile for the three cases are depicted. The error for the multi-channel measurement is overall better than that re-

15 trieved from the $\mathrm{THz}$ channel measurement. A large improvement can be found below $17.5 \mathrm{~km}$ with respect to that using the $\mathrm{GHz}$ channel only. The largest error appears around $20.5 \mathrm{~km}$ where the noise error (see Fig. 16b) is largest below the observer in the $\mathrm{THz}$ channel measurement.

These results indicate that the multi-channel simultaneous retrieval can help to im20 prove the quality of the retrieval by significantly better exploitation of information from the observations. Furthermore, the multi-channel fitting requires less iteration steps than both single-channel cases.

\section{Conclusions}

We have presented the retrieval code PILS for infrared/microwave limb sounding and 25 applied it to the TELIS level-2 data processing. Compared to most stochastic data models used in the literature, our data analysis operates in a semi-stochastic setting. The forward model is based on an optimized line-by-line code, coupled with automatic

$$
277
$$

differentiation for evaluating Jacobians accurately and efficiently, and the inversion employs nonlinear least squares fitting with direct and iterative multi-parameter regularization methods.

A sensitivity study of hydroxyl radical $(\mathrm{OH})$ retrieval from spectra recorded by the 5 TELIS $1.8 \mathrm{THz}$ channel has been given, assuming a single limb scan with a worst case signal-noise-ratio, but otherwise perfect instrumental knowledge. Both single- and multi-profile retrieval frameworks perform in decent quality. The results illustrate that $\mathrm{OH}$ can be derived from the TELIS observations in the lower and middle stratosphere. The relative retrieval error is typically $25 \%$ at the lowest altitude due to the a priori

o knowledge and gradually improves with increasing altitude where the retrieval error is dominated by the noise error.

Furthermore, a sensitivity analysis on potential error sources has been conducted. We have simulated the calibration procedure in the forward model and retrieved $\mathrm{OH}$ from the calibrated measurements distorted by nonlinearity. The calibration error, mainly the nonlinearity effect, does not introduce a severe error on the $\mathrm{OH}$ retrieval.

However, the inaccurate knowledge of the receiver sideband ratio is estimated to induce an error in the retrieval, because the strong $\mathrm{OH}$ line lies in the upper sideband in the selected frequency microwindow. The results are found to be more severely influenced by larger biases. In particular, the pointing error could be another major 20 error source for the $\mathrm{OH}$ retrieval.

The propagated errors due to the atmospheric profiles have also been investigated. The $\mathrm{OH}$ retrieval is very sensitive to the errors in the temperature and pressure profiles at lower altitudes where the concentration is rather low.

Besides, the capability of multi-channel simultaneous retrieval of hydrogen chloride $25(\mathrm{HCl})$ from the far infrared and submillimeter observations has been studied. The errors and averaging kernels demonstrate the improvement on the retrieval quality, particularly over the lower altitude range.

There are some important issues to be resolved, such as pointing retrieval, reliable temperature profile, and errors in spectroscopic parameters and continuum model. Our 
current/future work focuses on analysis of the real measurement data from the three Kiruna campaigns, and we begin with the $\mathrm{O}_{3}$ retrieval (see Kasai et al., 2013).

Acknowledgements. The authors would like to thank M. Birk and G. Wagner from DLR, A. de Lange and J. Landgraf from SRON for fruitful discussions on the TELIS measurement and

5 its relevance to atmospheric research. Financial support for JX by the German Academic Exchange Service (DAAD) is appreciated.

The service charges for this open access publication

have been covered by a Research Centre of the

10 Helmholtz Association.

\section{References}

Anderson, G., Clough, S., Kneizys, F., Chetwynd, J., and Shettle, E.: AFGL atmospheric constituent profiles (0-120 km), Tech. Rep. TR-86-0110, AFGL, 1986. 263

Bakushinskii, A.: The problem of the convergence of the iteratively regularized Gauss-Newton method, Comput. Math. Phys., 32, 1353-1359, 1992. 259

Baron, P., Urban, J., Sagawa, H., Möller, J., Murtagh, D. P., Mendrok, J., Dupuy, E., Sato, T. O., Ochiai, S., Suzuki, K., Manabe, T., Nishibori, T., Kikuchi, K., Sato, R., Takayanagi, M., Murayama, Y., Shiotani, M., and Kasai, Y.: The Level 2 research product algorithms for the Superconducting Submillimeter-Wave Limb-Emission Sounder (SMILES), Atmos. Meas. Tech., 4, 2105-2124, doi:10.5194/amt-4-2105-2011, 2011. 268

Birk, M., Wagner, G., de Lange, G., de Lange, A., Ellison, B. N., Harman, M. R., Murk, A., Oelhaf, H., Maucher, G., and Sartorius, C.: TELIS: TErahertz and subMMW LImb Sounder Project Summary After First Sucessful Flight, in: Proceedings of 21st International Symposium on Space Terahertz Technology, University of Oxford and STFC Rutherford Appleton 25 Laboratory, 195-200, 2010. 263

Bischof, C., Carle, A., Hovland, P., Khademi, P., and Mauer, A.: ADIFOR 2.0 User's Guide (Revision D), Tech. Rep. ANL/MCS-TM-192, Argonne National Laboratory - Mathematics and Computer Science Division, 1998. 261

Bischof, C. H. and Bücker, H. M.: Computing Derivatives of Computer Programs, in: Modern Methods and Algorithms of Quantum Chemistry: Proceedings, edited by: Grotendorst, J., 279

2nd Edn., NIC Series, Vol. 3, John von Neumann Institute for Computing, Jülich, 315-327, 2000. 262

Carli, B., Carlotti, M., Dinelli, B., Mencaraglia, F., and Park, J.: The mixing ratio of stratospheric hydroxyl radical from far infrared emission measurements, J. Geophys. Res., 94, 1104911058, doi:10.1029/JD094iD08p11049, 1989. 254

Carlotti, M.: Global-fit approach to the analysis of limb-scanning atmospheric measurements, Appl. Opt., 27, 3250-3254, doi:10.1364/AO.27.003250, 1988. 257

Carlotti, M., Ade, P., Carli, B., Chipperfield, M., Hamilton, P., Mencaraglia, F., Nolt, I., and Ridolfi, M.: Diurnal variability and night detection of stratospheric hydroxyl radical from far infrared

10 emission measurements, J. Atmos. Sol.-Terr. Phys., 63, 1509-1518, doi:10.1016/S13646826(01)00030-X, 2001. 254

Ceccherini, S., Carli, B., Cortesi, U., Bianco, S. D., and Raspollini, P.: Retrieval of the vertical column of an atmospheric constituent from data fusion of remote sensing measurements, J. Quant. Spectrosc. Ra., 111, 507-514, doi:10.1016/j.jqsrt.2009.09.001, 2010. 275

15 Clough, S., Kneizys, F., and Davies, R.: Line shape and the water vapor continuum, Atmos. Res., 23, 229-241, doi:10.1016/0169-8095(89)90020-3, 1989. 262

de Lange, A., Landgraf, J., and Hoogeveen, R.: Stratospheric isotopic water profiles from a single submillimeter limb scan by TELIS, Atmos. Meas. Tech., 2, 423-435, doi:10.5194/amt2-423-2009, 2009. 255, 256, 268

20 de Lange, A., Birk, M., de Lange, G., Friedl-Vallon, F., Kiselev, O., Koshelets, V., Maucher, G., Oelhaf, H., Selig, A., Vogt, P., Wagner, G., and Landgraf, J.: $\mathrm{HCl}$ and $\mathrm{ClO}$ in activated Arctic air; first retrieved vertical profiles from TELIS submillimetre limb spectra, Atmos. Meas. Tech., 5, 487-500, doi:10.5194/amt-5-487-2012, 2012. 268

de Lange, G., Birk, M., Boersma, D., Derckson, J., Dmitriev, P., Ermakov, A., Filippenko, L.,

25 Golstein, H., Hoogeveen, R., de Jong, L., Khudchenko, A., Kinev, N., Kiselev, O., van Kuik, B., de Lange, A., van Rantwijk, J., Selig, A., Sobolev, A., Torgashin, M., de Vries, E., Wagner, G., Yagoubov, P., and Koshelets, V.: Development and characterization of the superconducting integrated receiver channel of the TELIS atmospheric sounder, Supercond. Sci. Technol., 23, 045016, doi:10.1088/0953-2048/23/4/045016, 2010. 253

30 Dennis Jr., J., Gay, D., and Welsch, R.: An adaptive nonlinear least-squares algorithm, ACM Trans. Math. Soft., 7, 348-368, doi:10.1145/355958.355965, 1981. 262 
Doicu, A., Trautmann, T., and Schreier, F.: Numerical Regularization for Atmospheric Inverse Problems, Springer and Praxis Publishing, Berlin Heidelberg, XIII, 1-426, doi:10.1007/9783-642-05439-6, 2010. 258, 259

Englert, C., Schimpf, B., Birk, M., Schreier, F., Krocka, M., Nitsche, R., Titz, R., and Summers, M.: The 2.5 THz heterodyne spectrometer THOMAS: Measurement of $\mathrm{OH}$ in the middle atmosphere and comparison with photochemical model results, J. Geophys. Res., 105, 22211-22223, doi:10.1029/2000JD900305, 2000. 255

Fischer, H., Birk, M., Blom, C., Carli, B., Carlotti, M., von Clarmann, T., Delbouille, L., Dudhia, A., Ehhalt, D., Endemann, M., Flaud, J. M., Gessner, R., Kleinert, A., Koopman, R., Langen, J., López-Puertas, M., Mosner, P., Nett, H., Oelhaf, H., Perron, G., Remedios, J., Ridolfi, M., Stiller, G., and Zander, R.: MIPAS: an instrument for atmospheric and climate research, Atm. Chem. Phys., 8, 2151-2188, doi:10.5194/acp-8-2151-2008, 2008. 275

Fox, P., Hall, A., and Schryer, N.: The PORT Mathematical Subroutine Library, ACM Trans. Math. Soft., 4, 104-126, doi:10.1145/355780.355789, 1978. 262

15 Friedl-Vallon, F., Maucher, G., Seefeldner, M., Trieschmann, O., Kleinert, A., Lengel, A., Keim, C., Oelhaf, H., and Fischer, $H$. .: Design and characterization of the balloon-borne Michelson Interferometer for Passive Atmospheric Sounding (MIPAS-B2), Appl. Opt., 43, 3335-3355, doi:10.1364/AO.43.003335, 2004. 253, 273

Griewank, A.: Evaluating Derivatives: Principles and Techniques of Algorithmic Differentiation, SIAM, Philadelphia, PA, 2000. 261

Hascoët, L. and Pascual, V.: The Tapenade automatic differentiation tool: Principles, model, and specification, ACM Trans. Math. Soft., 39, 3, doi:10.1145/2450153.2450158, 2013. 261

Hedelt, P., Alonso, R., Brown, T., Collados Vera, M., Rauer, H., Schleicher, H., Schmidt, W., Schreier, F., and Titz, R.: Venus transit 2004: Illustrating the capability of exoplanet transmission spectroscopy, A\& A, 533, A136, doi:10.1051/0004-6361/201016237, 2011. 261

Jucks, K., Johnson, D., Chance, K., Traub, W., Margitan, J., Osterman, G., Salawitch, R., and Sasano, Y.: Observations of $\mathrm{OH}, \mathrm{HO}_{2}, \mathrm{H}_{2} \mathrm{O}$, and $\mathrm{O}_{3}$ in the upper stratosphere: Implications for $\mathrm{HO}_{\mathrm{x}}$ photochemistry, Geophys. Res. Lett., 25, 3935-3938, doi:10.1029/1998GL900009, 1998. 254

so Kasai, Y., Sagawa, H., Kreyling, D., Suzuki, K., Dupuy, E., Sato, T. O., Mendrok, J., Baron, P., Nishibori, T., Mizobuchi, S., Kikuchi, K., Manabe, T., Ozeki, H., Sugita, T., Fujiwara, M., Irimajiri, Y., Walker, K. A., Bernath, P. F., Boone, C., Stiller, G., von Clarmann, T., Orphal, J., Urban, J., Murtagh, D., Llewellyn, E. J., Degenstein, D., Bourassa, A. E., Lloyd, N. D., Froidevaux,

281

L., Birk, M., Wagner, G., Schreier, F., Xu, J., Vogt, P., Trautmann, T., and Yasui, M.: Validation of stratospheric and mesospheric ozone observed by SMILES from International Space Station, Atmos. Meas. Tech. Discuss., 6, 2643-2720, doi:10.5194/amtd-6-2643-2013, 2013. 279

5 Kikuchi, K., Nishibori, T., Ochiai, S., Ozeki, H., Irimajiri, Y., Kasai, Y., Koike, M., Manabe, T., Mizukoshi, K., Murayama, Y., Nagahama, T., Sano, T., Sato, R., Seta, M., Takahashi, C., Takayanagi, M., Masuko, H., Inatani, J., Suzuki, M., and Shiotani, M.: Overview and early results of the Superconducting Submillimeter-Wave Limb-Emission Sounder (SMILES), J. Geophys. Res., 115, D23306, doi:10.1029/2010JD014379, 2010. 253

10 Landgraf, J. and Hasekamp, O. P.: Retrieval of tropospheric ozone: The synergistic use of thermal infrared emission and ultraviolet reflectivity measurements from space, J. Geophys. Res., 112, D08310, doi:10.1029/2006JD008097, 2007. 275

Liou, K.-N.: An Introduction to Atmospheric Radiation, Academic Press, 2nd Edn., 2002. 256

Mair, U., Krocka, M., Wagner, G., Birk, M., Hübers, H.-W., Richter, H., Semenov, A., Hoogeveen,

15 R., de Graauw, T., Yagoubov, P., Maurellis, A., Selig, A., Koshelets, V., Shitov, S., Goltsman, G., Voronov, B., Ellison, B., Kerridge, B., Matheson, D., Siddans, R., and Reburn, J.: TELIS Development of a New Balloon Borne THz/Submm Heterodyne Limb Sounder, in: Proceedings of the 14. International Symposium on Space Terahertz Technology, Tucson, AZ, USA, April 2003, 204-214, 2004. 255

20 Melsheimer, C., Verdes, C., Bühler, S., Emde, C., Eriksson, P., Feist, D., Ichizawa, S., John, V., Kasai, Y., Kopp, G., Koulev, N., Kuhn, T., Lemke, O., Ochiai, S., Schreier, F., Sreerekha, T., Suzuki, M., Takahashi, C., Tsujimaru, S., and Urban, J.: Intercomparison of general purpose clear sky atmospheric radiative transfer models for the millimeter/submillimeter spectral range, Radio Sci., 40, RS1007, doi:10.1029/2004RS003110, 2005. 261

25 Mendrok, J., Schreier, F., and Höpfner, M.: Estimating cirrus cloud properties from MIPAS data, Geophys. Res. Lett., 34, L08807, doi:10.1029/2006GL028246, 2007. 261

Minschwaner, K., Manney, G. L., Wang, S. H., and Harwood, R. S.: Hydroxyl in the stratosphere and mesosphere - Part 1: Diurnal variability, Atmos. Chem. Phys., 11, 955-962, doi:10.5194/acp-11-955-2011, 2011. 255

30 Murtagh, D., Frisk, U., Merino, F., Ridal, M., Jonsson, A., Stegman, J., Witt, G., Eriksson, P., Jiménez, C., Megie, G., de la Noë, J., Ricaud, P., Baron, P., Pardo, J. R., Hauchcorne, A., Llewellyn, E. J., Degenstein, D. A., Gattinger, R. L., Lloyd, N. D., Evans, W. F., McDade, I. C., Haley, C. S., Sioris, C., von Savigny, C., Solheim, B. H., McConnell, J. C., Strong, 
K., Richardson, E. H., Leppelmeier, G. W., Kyrölä, E., Auvinen, H., and Oikarinen, L.: An overview of the Odin atmospheric mission, Can. J. Phys., 80, 309-319, doi:10.1139/p01157, 2002. 252

Pickett, $\mathrm{H}$. and Peterson, D.: Stratospheric $\mathrm{OH}$ Measurements with a far-infrared limb observing spectrometer, J. Geophys. Res., 98, 20507-20515, 1993. 254

Rodgers, C.: Inverse Methods for Atmospheric Sounding: Theory and Practise, World Scientific, Singapore, 2000. 258

Rothman, L., Gordon, I., Barbe, A., Benner, D. C., Bernath, P., Birk, M., Boudon, V., Brown, L., Campargue, A., Champion, J.-P., Chance, K., Coudert, L., Dana, V., Devi, V., Fally, S., Flaud, J.-M., Gamache, R., Goldman, A., Jacquemart, D., Kleiner, I., Lacome, N., Lafferty, W., Mandin, J.-Y., Massie, S., Mikhailenko, S., Miller, C., Moazzen-Ahmadi, N., Naumenko, O., Nikitin, A., Orphal, J., Perevalov, V., Perrin, A., Predoi-Cross, A., Rinsland, C., Rotger, M., Simecková, M., Smith, M., Sung, K., Tashkun, S., Tennyson, J., Toth, R., Vandaele, A., and Auwera, J. V.: The HITRAN 2008 molecular spectroscopic database, J. Quant. Spectrosc. Ra., 110, 533-572, doi:10.1016/j.jqsrt.2009.02.013, 2009. 262

Schreier, F.: Optimized evaluation of a large sum of functions using a three-grid approach, Comp. Phys. Comm., 174, 783-802, doi:10.1016/j.cpc.2005.12.015, 2006. 261

Schreier, F.: Optimized implementations of rational approximations for the Voigt and complex error function, J. Quant. Spectrosc. Ra., 112, 1010-1025, doi:10.1016/j.jqsrt.2010.12.010, 2011. 261

Schreier, F. and Böttger, U.: MIRART, A line-by-line code for infrared atmospheric radiation computations incl. derivatives, Atmos. Ocean. Opt., 16, 262-268, 2003. 261

Schreier, F. and Schimpf, B.: A New Efficient Line-By-Line Code for High Resolution Atmospheric Radiation Computations incl. Derivatives, in: IRS 2000: Current Problems in Atmospheric Radiation, edited by: Smith, W. and Timofeyev, Y., A. Deepak Publishing, 381-384, 2001. 261

Suttiwong, N.: Development and characteristics of the balloon borne instrument TELIS (TEhertz and submillimeter LImb Sounder): $1.8 \mathrm{THz}$ receiver, Ph.D. Thesis, University of Bremen, 2010. 254, 257

30 Suttiwong, N., Birk, M., Wagner, G., Krocka, M., Wittkamp, M., Haschberger, P., Vogt, P., and Geiger, F.: Development and characterization of the balloon borne instrument TELIS (TEhertz and Submm LImb Sounder): 1.8 THz receiver, in: Proc. 19th ESA Symposium on

European Rocket and Balloon Programmes and Related Research, Bad Reichenhall, Germany, 2009. 253

Tikhonov, A.: On the Solution of Incorrectly Stated Problems and a Method of Regularization, Dokl. Acad. Nauk SSSR, 151, 501-504, 1963. 257

5 Ungermann, J., Blank, J., Lotz, J., Leppkes, K., Hoffmann, L., Guggenmoser, T., Kaufmann, M., Preusse, P., Naumann, U., and Riese, M.: A 3-D tomographic retrieval approach with advection compensation for the air-borne limb-imager GLORIA, Atmos. Meas. Tech., 4, 25092529, doi:10.5194/amt-4-2509-2011, 2011. 261

Urban, J., Lautié, N., Flochmoën, E. L., Jiménez, C., Eriksson, P., Dupuy, E., Amraoui, L. E., Ekström, M., Frisk, U., Murtagh, D., de La Noë, J., Olberg, M., and Ricaud, P.: Odin/SMR limb observations of stratospheric trace gases: Level 2 processing of $\mathrm{ClO}, \mathrm{N}_{2} \mathrm{O}, \mathrm{O}_{3}$, and $\mathrm{HNO}_{3}$, J. Geophys. Res., 110, D14, doi:10.1029/2004JD005741, 2005. 268

Vasquez, M., Gottwald, M., Gimeno García, S., Krieg, E., Lichtenberg, G., Slijkhuis, S., Schreier, F., Snel, R., and Trautmann, T.: Venus observations from ENVISAT-SCIAMACHY: Measurements and modeling, Adv. Space Res., 51, 835-848, doi:10.1016/j.asr.2012.09.046, 2013. 261

von Clarmann, T., Höpfner, M., Funke, B., López-Puertas, M., Dudhia, A., Jay, V., Schreier, F., Ridolfi, M., Ceccherini, S., Kerridge, B., Reburn, J., and Siddans, R.: Modeling of atmospheric mid-infrared radiative transfer: the AMIL2DA algorithm intercomparison experiment, J. Quant. Spectrosc. Ra., 78, 381-407, doi:10.1016/S0022-4073(02)00262-5, 2002. 261

Waters, J., Froidevaux, L., Harwood, R., Jarnot, R., Pickett, H., Read, W., Siegel, P., Cofield, R., Filipiak, M., Flower, D., Holden, J., Lau, G., Livesey, N., Manney, G., Pumphrey, H., Santee, M., Wu, D., Cuddy, D., Lay, R., Loo, M., Perun, V., Schwartz, M., Stek, P., Thurstans, R., Boyles, M., Chandra, K., Chavez, M., Chen, G.-S., Chudasama, B., Dodge, R., Fuller, R., Gi-

25 rard, M., Jiang, J., Jiang, Y., Knosp, B., LaBelle, R., Lam, J., Lee, K., Miller, D., Oswald, J., Patel, N., Pukala, D., Quintero, O., Scaff, D., Van Snyder, W., Tope, M., Wagner, P., and Walch, M.: The Earth observing system microwave limb sounder (EOS MLS) on the Aura Satellite, IEEE Trans. Geosci. Remote Sens., 44, 1075-1092, doi:10.1109/TGRS.2006.873771, 2006. 253

30 Zdunkowski, W., Trautmann, T., and Bott, A.: Radiation in the Atmosphere - A Course in Theoretical Meteorology, Cambridge University Press, 2007. 256 
Table 1. Major instrument and geometry parameters used for simulating the synthetic spectra observed for the $\mathrm{OH}$ microwindow. The channel notation $\mathrm{THz}$ stands for the $1.8 \mathrm{THz}$ channel.

\begin{tabular}{ll}
\hline Parameter & Description \\
\hline Channel & $\mathrm{THz}$ \\
LO frequency & $1830.10 \mathrm{GHz}$ \\
Intermediate frequency & $4-6 \mathrm{GHz}$ \\
Spectral resolution & $2.16 \mathrm{MHz}$ \\
ILS function & Hamming apodization \\
Field-of-view (FWHM) & Gaussian (6.3 arcmin) \\
Sideband ratio & 1.0 \\
Signal-to-noise ratio & 35 \\
Top-of-atmosphere & $85 \mathrm{~km}$ \\
Observing altitude & $35 \mathrm{~km}$ \\
Tangent altitudes & $15-33 \mathrm{~km}$ \\
Vertical sampling & $2 \mathrm{~km}$ \\
\hline
\end{tabular}

Table 2. Major instrument and geometry settings for multi-channel retrieval simulation. The channel notation $\mathrm{GHz}$ stands for the $480-650 \mathrm{GHz}$ channel.

\begin{tabular}{llc}
\hline Parameter & \multicolumn{2}{c}{ Description } \\
\hline Channel & $\mathrm{THz}$ & $\mathrm{GHz}$ \\
LO frequency & $1877.63 \mathrm{GHz}$ & $619.10 \mathrm{GHz}$ \\
Intermediate frequency & $4-6 \mathrm{GHz}$ & $5-7 \mathrm{GHz}$ \\
ILS function & Hamming apodization & Lorentzian \\
Field-of-view (FWHM) & Gaussian (6.3 arcmin) & Gaussian (10.8 arcmin) \\
Signal-to-noise ratio & 30 & 110 \\
Top-of-atmosphere & & $85 \mathrm{~km}$ \\
Observing altitude & $34 \mathrm{~km}$ \\
Tangent altitudes & & $10-32.5 \mathrm{~km}$ \\
Vertical sampling & & $1.5 \mathrm{~km}$ \\
\hline
\end{tabular}




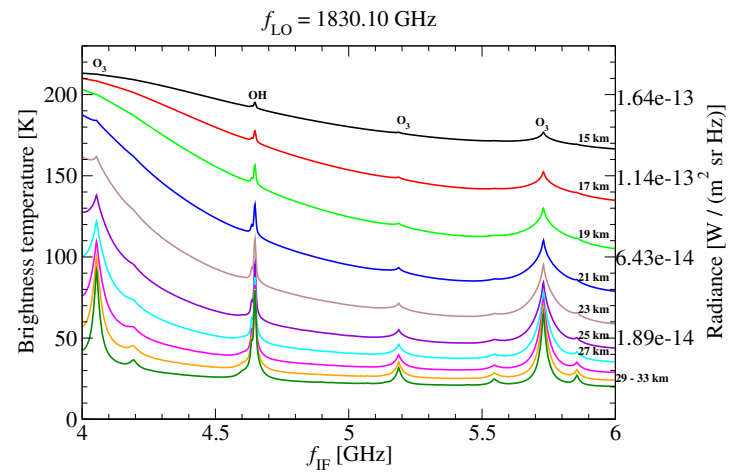

Fig. 1. Noise-free spectra (radiance and equivalent brightness temperature) simulated for a local oscillator frequency $f_{\mathrm{LO}}=1830.10 \mathrm{GHz}$ with an intermediate frequency range of $4-6 \mathrm{GHz}$, recording in double sideband mode with a sideband ratio of 1.0 . The flight altitude is $35 \mathrm{~km}$ and the tangent altitudes are given to the right of the panel.
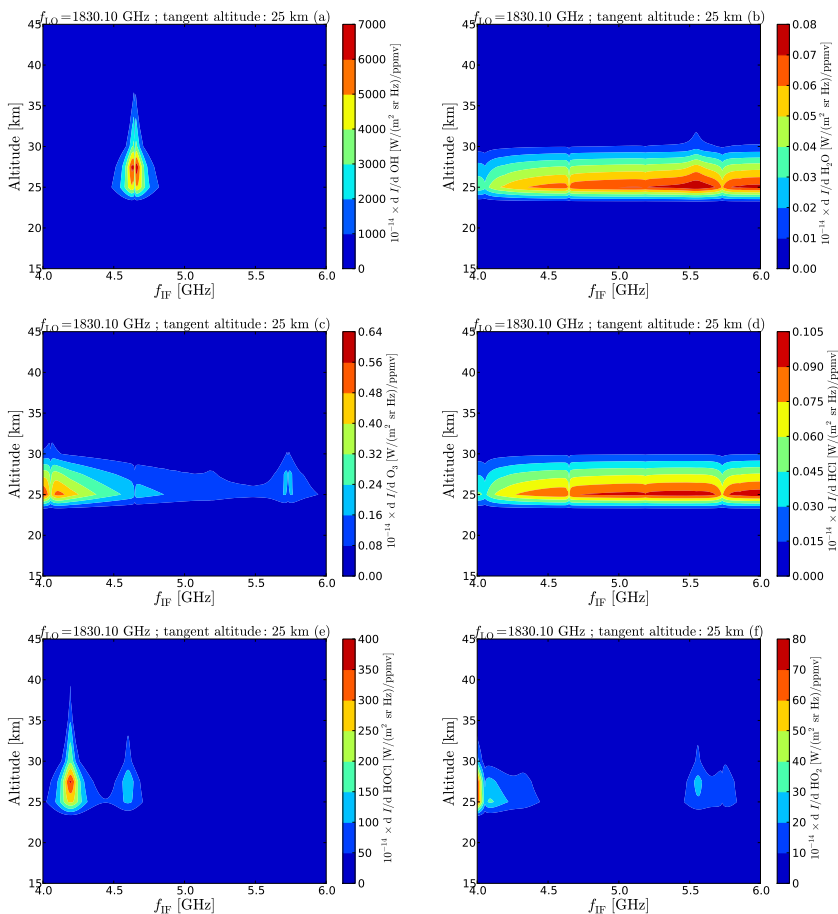

Fig. 2. Jacobian for molecular concentration profiles evaluated at an altitude grid between 15 and $45 \mathrm{~km}$ for a tangent altitude of $25 \mathrm{~km}$. The molecules are $\mathrm{OH}$ (a), $\mathrm{H}_{2} \mathrm{O}$ (b), $\mathrm{O}_{3}$ (c), $\mathrm{HCl}$ (d), $\mathrm{HOCl}(\mathbf{e})$, and $\mathrm{HO}_{2}(\mathbf{f})$. 

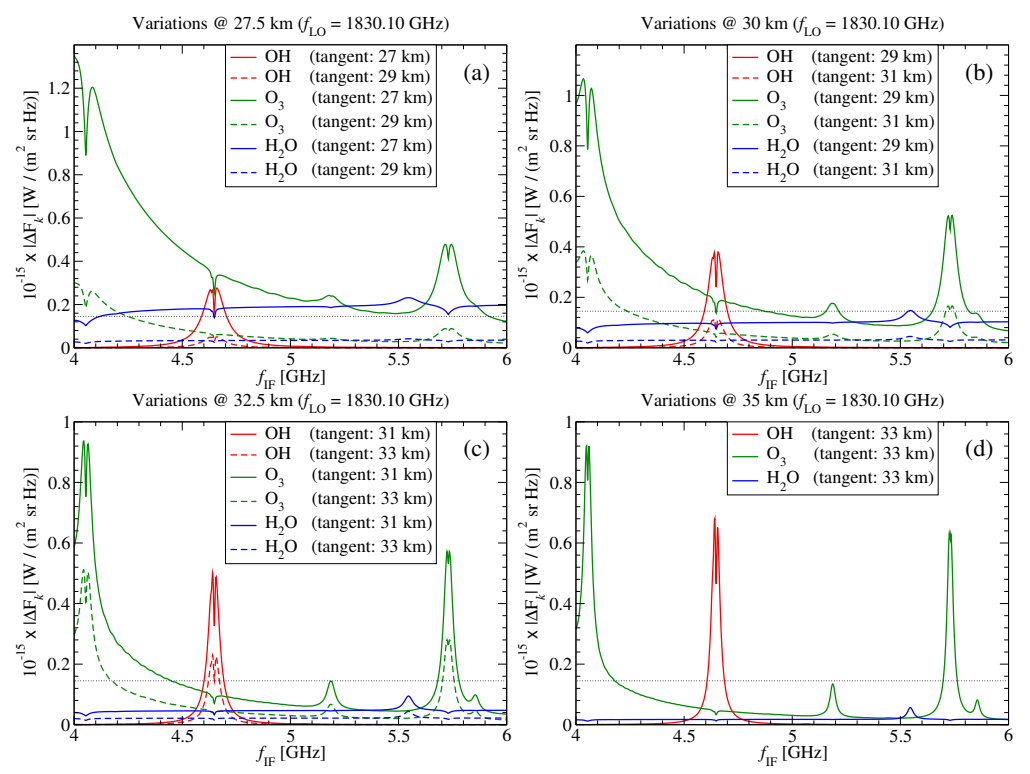

Fig. 3. Sensitivity study: variations of the limb radiances for a $10 \%$ variation of the concentration profiles of $\mathrm{OH}, \mathrm{O}_{3}$, and $\mathrm{H}_{2} \mathrm{O}$ at the altitude levels of 27.5 (a), 30 (b), 32.5 (c), and $35 \mathrm{~km}$ (d). The dotted horizontal lines delimit the noise domain.
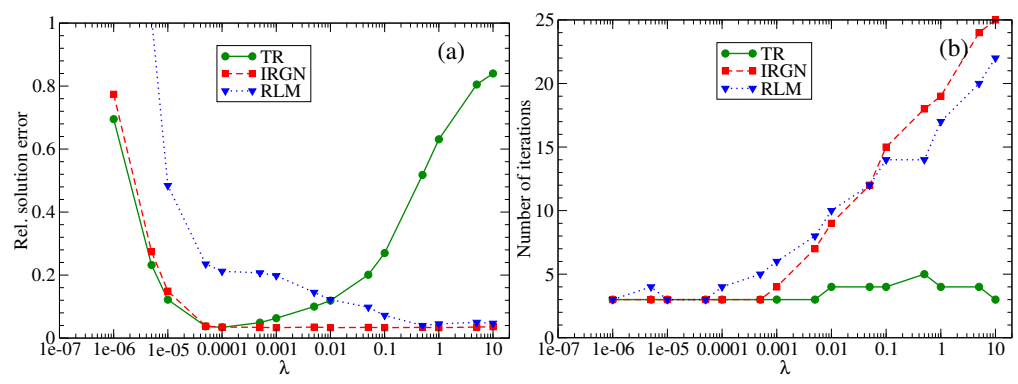

Fig. 4. Relative solution errors (a) and the number of iteration steps (b) for different values of the regularization parameter. The results are for one-profile retrieval of $\mathrm{OH}$ and correspond to Tikhonov regularization (TR), the iteratively regularized Gauss-Newton (IRGN) method, and the regularizing Levenberg-Marquardt (RLM) method. 

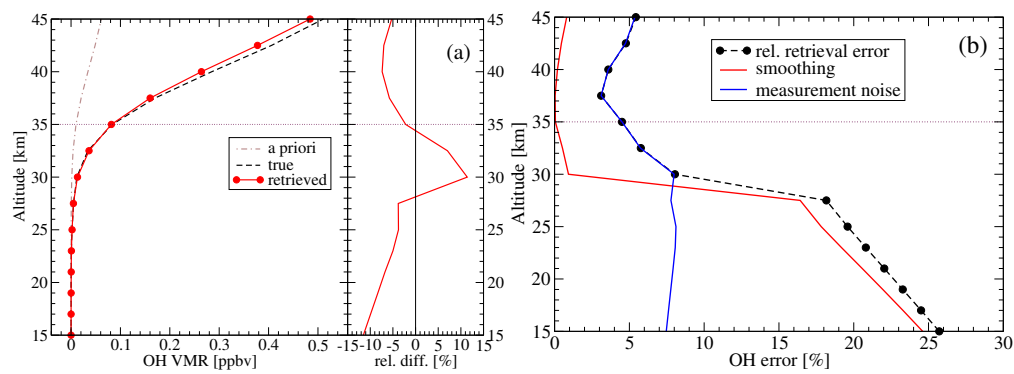

Fig. 5. Results of single $\mathrm{OH}$ retrieval and corresponding diagnostic quantities as a function of altitude. (a): retrieved VMR profile and corresponding errors in terms of relative difference with respect to the true profile. The dashed black line refers to the true profile. (b): corresponding properties of the retrieval, i.e. relative retrieval error, smoothing and noise errors.

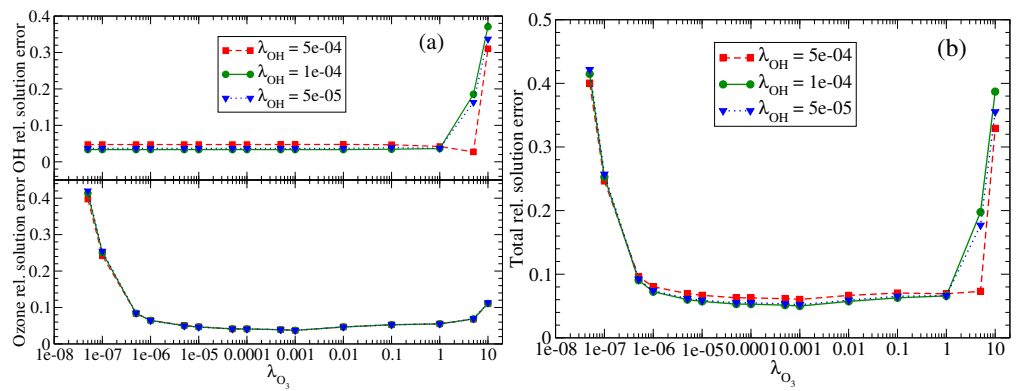

Fig. 6. Determination of the regularization parameters for two-profile retrieval of $\mathrm{OH}$ and $\mathrm{O}_{3}$. (a): relative solution errors of $\mathrm{OH}$ and $\mathrm{O}_{3}$ versus different regularization parameters of $\mathrm{OH}$ and $\mathrm{O}_{3}$. (b): total solution errors versus the regularization parameters of $\mathrm{OH}$ and $\mathrm{O}_{3}$. 


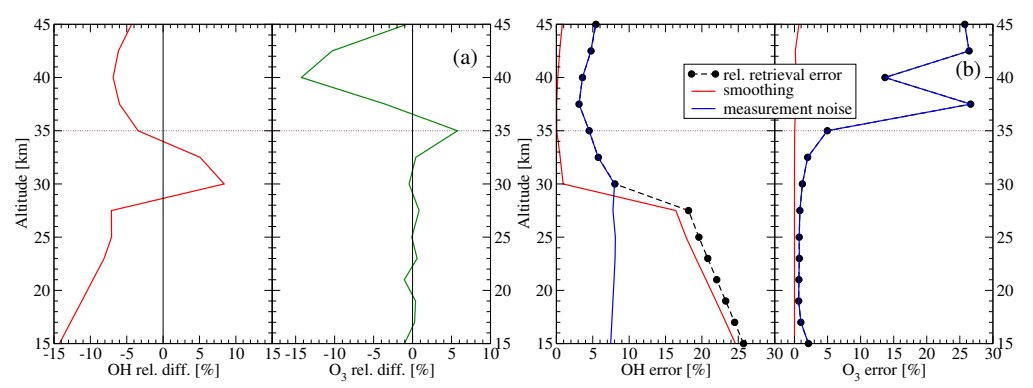

Fig. 7. Retrieval results for two-profile retrieval as a function of altitude. (a): relative differences for joint retrieval of $\mathrm{OH}$ and $\mathrm{O}_{3}$. (b): relative retrieval error, smoothing and noise errors for joint retrieval of $\mathrm{OH}$ and $\mathrm{O}_{3}$.

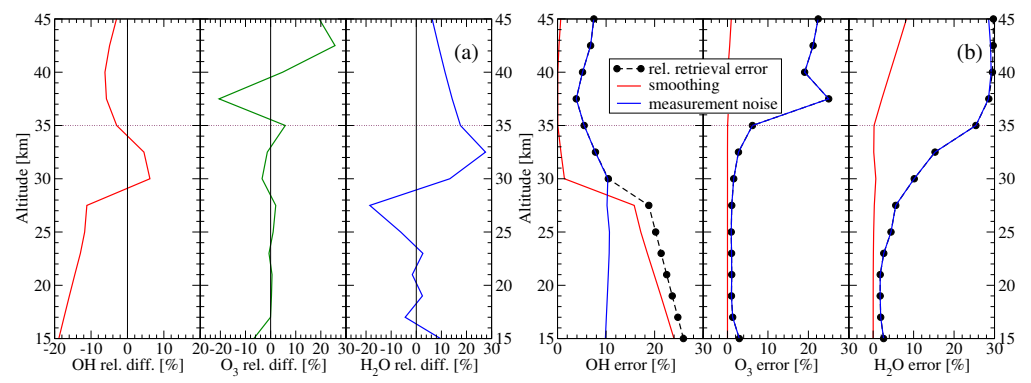

Fig. 8. Retrieval results for three-profile retrieval as a function of altitude. (a): relative differences for joint retrieval of $\mathrm{OH}, \mathrm{O}_{3}$, and $\mathrm{H}_{2} \mathrm{O}$. (b): relative retrieval error, smoothing and noise errors for joint retrieval of $\mathrm{OH}, \mathrm{O}_{3}$, and $\mathrm{H}_{2} \mathrm{O}$. 


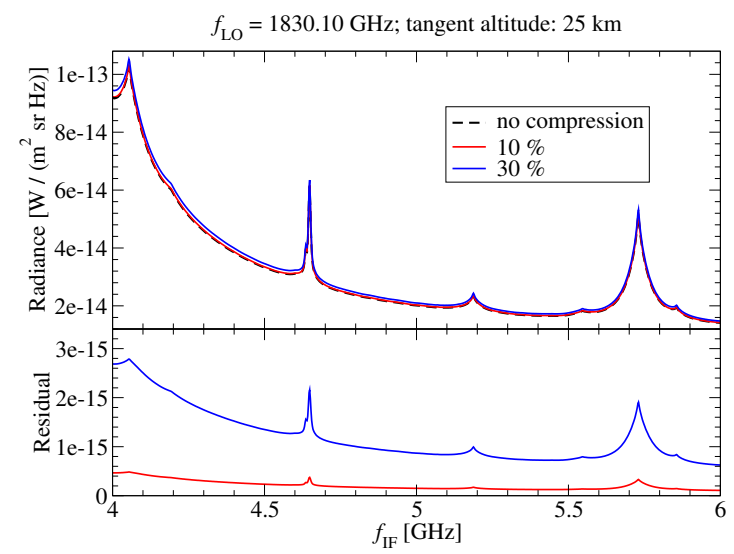

Fig. 9. Modelled calibrated spectrum measured at the tangent altitude of $25 \mathrm{~km}$ and corresponding residuals with respect to the pure model spectrum. The assumed compressions of 10 and $30 \%$ in the hot load measurement are taken into account.

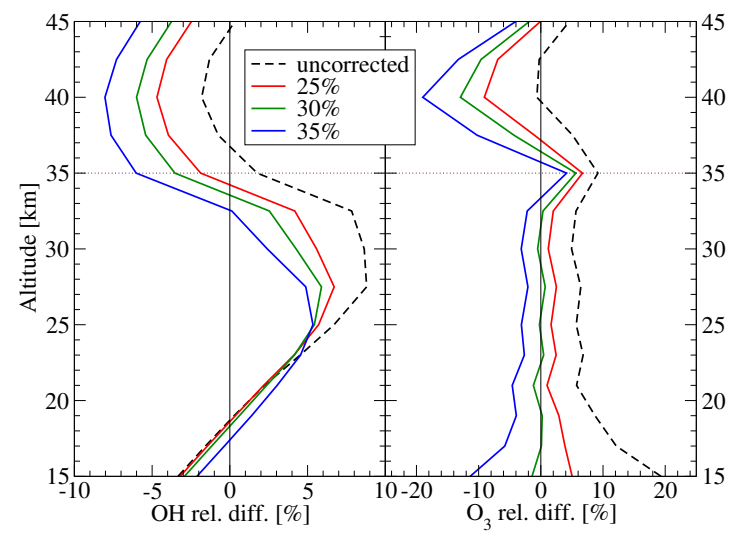

Fig. 10. Relative difference of $\mathrm{OH}$ and $\mathrm{O}_{3}$. The retrievals are done for the noisy synthetic measurements that are generated by the calibrated spectra with the compression of $30 \%$ in the hot load. $5 \%$ uncertainty is taken into account in the pseudo-correction procedure: the compression is set to 25 and $35 \%$ for two repeated retrievals. 

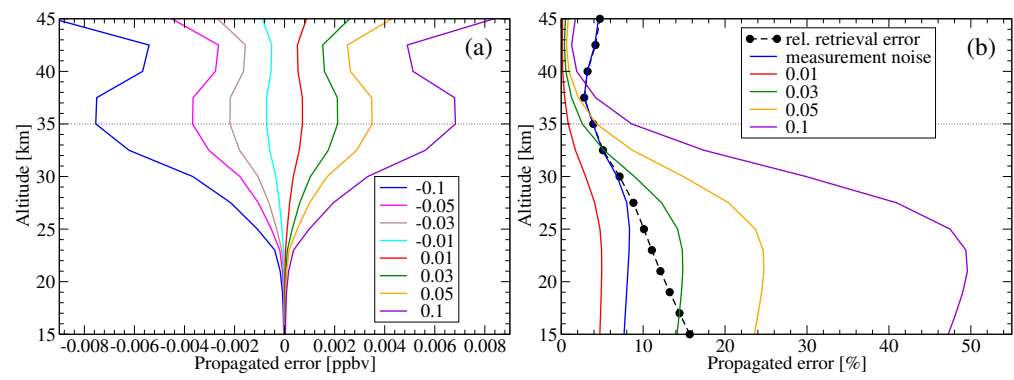

Fig. 11. Propagated error of sideband ratio onto the $\mathrm{OH}$ retrieval with the sideband ratio bias $\eta$. (a): results in terms of absolute unit (VMR) with respect to the values $\pm 0.01, \pm 0.03, \pm 0.05$, and \pm 0.1 for $\eta$. (b): results in terms of relative unit in percent of the true profile with respect to the positive values for $\eta$. For reference the retrieval error and the noise error caused by the measurement noise are included in this plot.

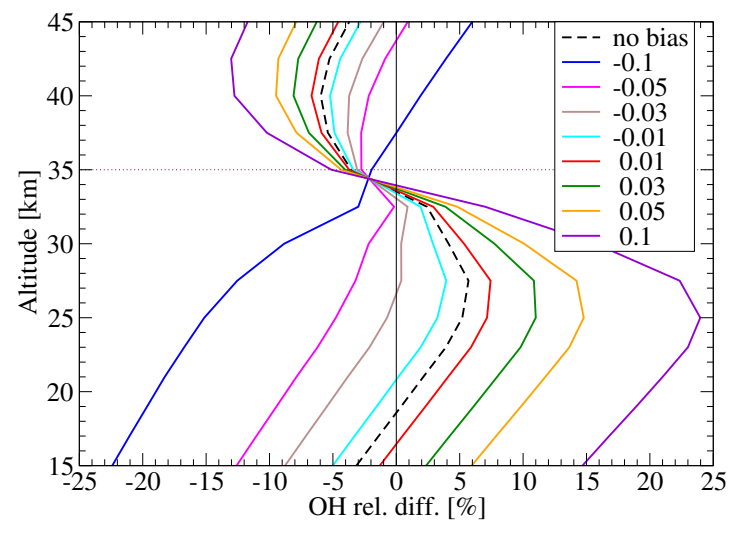

Fig. 12. Errors for $\mathrm{OH}$ retrieval in terms of relative difference with different values of relative bias $\eta$ in the sideband ratio. The retrievals are performed using the synthetic measurement for ideal sideband ratio $r=1.0$. For reference the retrieval result for the assumed sideband ratio $r=1.0$ is given in dashed black line. 

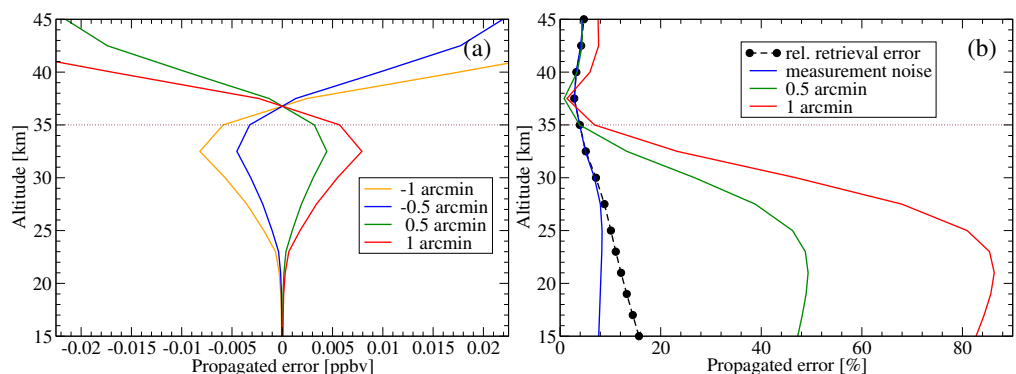

Fig. 13. Propagated error of pointing onto the $\mathrm{OH}$ retrieval with the error on the systematic pointing bias. By assuming \pm 0.5 and \pm 1 arcmin, respectively, the results in terms of absolute unit (a) and relative unit (b) with respect to the true profile are shown.
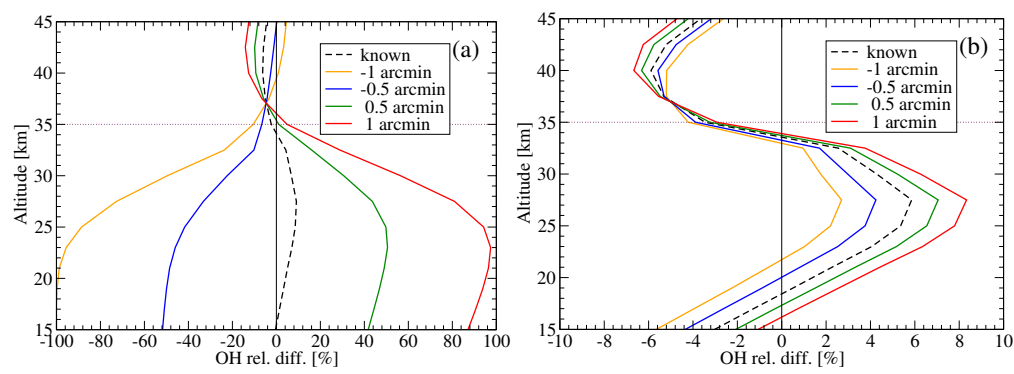

Fig. 14. Relative differences in the $\mathrm{OH}$ profile for single-target retrieval (a) and joint retrieval of $\mathrm{OH}$ and $\mathrm{O}_{3}$ (b) with uncertainties of 0.5 and 1 arcmin in the systematic pointing bias. For reference the retrieval result for the perfectly known pointing information is given in dashed black line. 

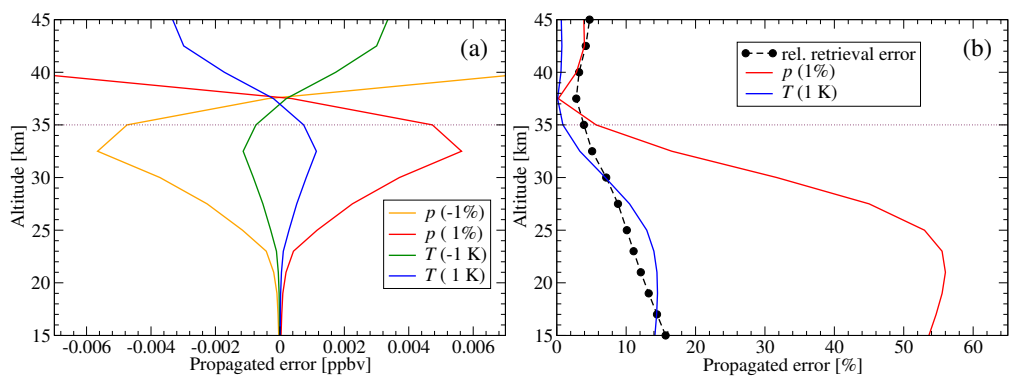

Fig. 15. Propagated errors of atmospheric profiles onto the $\mathrm{OH}$ retrieval. By assuming errors of -1 and $1 \mathrm{~K}$ in the temperature profile and errors of -1 and $1 \%$ in the pressure profile, respectively, the results in terms of absolute unit (a) and relative unit (b) with respect to the true profile are shown. The black dashed line refers to the retrieval error in case of the exact temperature profile.

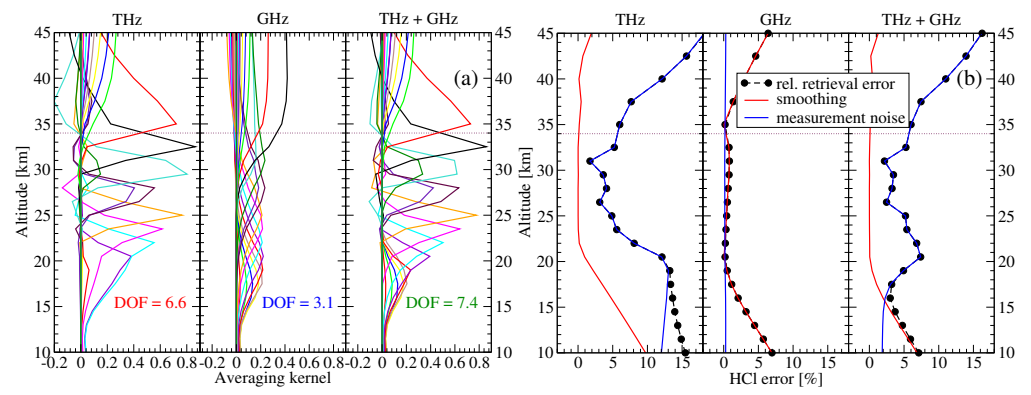

Fig. 16. (a): averaging kernels for $\mathrm{HCl}$ retrieval using the single-channel measurement in the 1.8 THz and $480-650 \mathrm{GHz}$ channels, and the multi-channel measurement in both channels. The notation DOF stands for the degree of freedom for signal. (b): relative retrieval error, smoothing and noise errors of $\mathrm{HCl}$ for the single- and multi-channel fitting. 


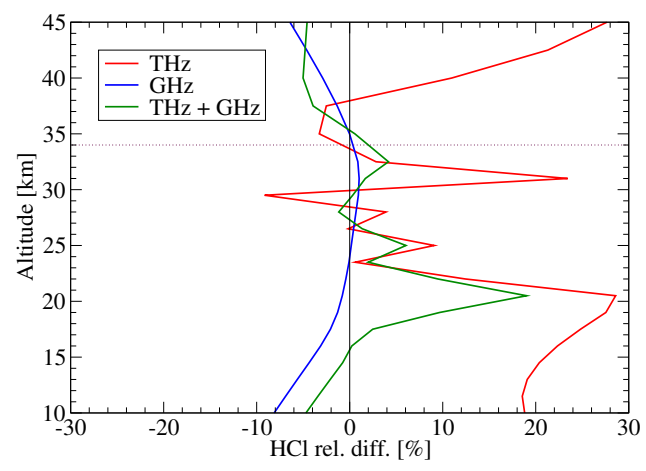

Fig. 17. Relative differences of $\mathrm{HCl}$ for the single- and multi-channel retrievals. The retrievals are done with the $\mathrm{THz}, \mathrm{GHz}$, and the combination of $\mathrm{THz}$ and $\mathrm{GHz}$ data, respectively. 